\title{
Quantitative Assessment of Dissipative Losses of 18 Metals
}

\author{
Christoph Helbig ${ }^{*}$, , Andrea Thorenz ${ }^{a}$, Axel Tuma ${ }^{a}$ \\ *Address correspondence to: christoph.helbig@wiwi.uni-augsburg.de \\ a: Resource Lab, Institute of Materials Resource Management, University of Augsburg, \\ Universitaetsstr. 16, 86159 Augsburg, Germany
}

Published in: Resources, Conservation and Recycling 153, 2020, 104537, https://doi.org/10.1016/j.resconrec.2019.104537

\begin{abstract}
Dissipative losses of metals are unrecoverable material flows representing the real consumption of metals. They occur during any process in the global metal cycle from primary production to waste management and have different receiving mediums. Avoiding dissipative losses can reduce both primary material requirements and potential negative environmental impacts of metals. However, there are currently no quantitative indicators available for the assessment of global dissipative losses of metals covering all processes before and after the use-phase. Here we present three indicators, the Dissipation-to-Extraction Ratio, the Dissipation-to-Final-Production Ratio, and the Expected Lifetime in the Anthroposphere. These indicators are further applied to 18 metals. The results show that the severity of dissipative losses throughout the periodic table differs a lot. Dissipation ratios are lowest for mass metals like iron, aluminum, and nickel, and highest for technology metals like gallium, germanium, and tellurium. Expected lifetimes vary between just months for metals with high dissipation ratios and up to a century for aluminum and iron. The assessment shows that there are important measures in material efficiency and recycling efforts to be taken to decrease dissipative losses for a wide range of metals. For each metal, the most effective options for action can be identified based on our results.
\end{abstract}

\section{Keywords}

dissipation; dissipative losses; material flow analysis; recycling; criticality; metals. 


\section{Introduction}

Metals are destroyed neither through extraction nor through utilization, because no matter what chemical compound they form, the atom persists. Therefore, dissipative losses should be considered the real consumption of metals. According to the definition of Zimmermann and Gößling-Reisemann, dissipative losses are material flows into a receiving medium that "result in concentrations [...] such that a recovery of these materials is technically or economically unfeasible" (Zimmermann \& GößlingReisemann, 2013).

Dissipative losses of metals have so far been studied with different perspectives. Lifset and colleagues (Lifset, Eckelman, Harper, Hausfather, \& Urbina, 2012) primarily differentiate between intended and unintended use and release of copper. In their article about critical metals, Zimmermann and Gößling-Reisemann (Zimmermann \& Gößling-Reisemann, 2013) focus on the receiving mediums of dissipative losses: landfills, other material flows and the environment. Ciacci and colleagues (Ciacci, Reck, Nassar, \& Graedel, 2015) highlight different levels of recyclability of metals depending on their application and later on quantify the energy requirements as well as greenhouse gas emissions associated with dissipative losses (Ciacci, Harper, Nassar, Reck, \& Graedel, 2016). Rechberger and Graedel (Rechberger \& Graedel, 2002) quantify the distribution patterns of copper throughout life cycle stages by applying their statistical entropy method. Finally, Nakamura and colleagues (Nakamura et al., 2014) use the MaTrace model to quantify which processes in the steel cycle cause dissipative losses at which time. Overall, quantifying dissipative losses globally is a difficult task, because we can only indirectly quantify what has been dispersed by looking at mass balances or by scaling up local measurements.

Both the share of individual metals in the lithosphere as well as applications of metals in the anthroposphere vary a lot (Thomas E. Graedel, Harper, Nassar, \& Reck, 2015; Rudnick \& Gao, 2003). Hence, it can be assumed that the range of observed dissipation rates is quite high. However, both the data and suitable indicators for a quantitative assessment of dissipative losses of a large variety of metals are so far missing. Problems linked with dissipation of metals also include effects like bioactivity, photo activity or water-solubility (Reller, 2016).

Figure 1 shows the conceptual model for global anthropogenic material flows of metals (Chen \& Graedel, 2012). Metals are typically extracted from the lithosphere by mining or quarrying, either directly as host metals or indirectly as by-products and then separated later on in the smelting or refining stage (Nedal T. Nassar, Graedel, \& Harper, 2015). Extracted materials are processed further in the fabrication and manufacturing stage before entering the use-phase through metal-containing products. The entrance into the use-phase will be called final production. Most metal products stay in the use-phase for multiple years and their purpose is predominantly fulfilled by in-use stocks like buildings, infrastructure, cars, or machinery. Rarely is the purpose the final production itself, and if that is the case, it's a dissipative use such as copper for pesticides (Lifset et al., 2012). The use-phase is followed by a waste management stage. Old scraps and new scraps are either directly modeled as reverse material flows or re-distributed within a scrap market process. Dissipative losses can occur at any stage from mining to waste management and may include material flows into tailings \& slags close to mining activities, direct emissions into the environment, losses to other materials (i.e. as contaminants in other metal cycles) and landfills or similar permanent waste disposals. 


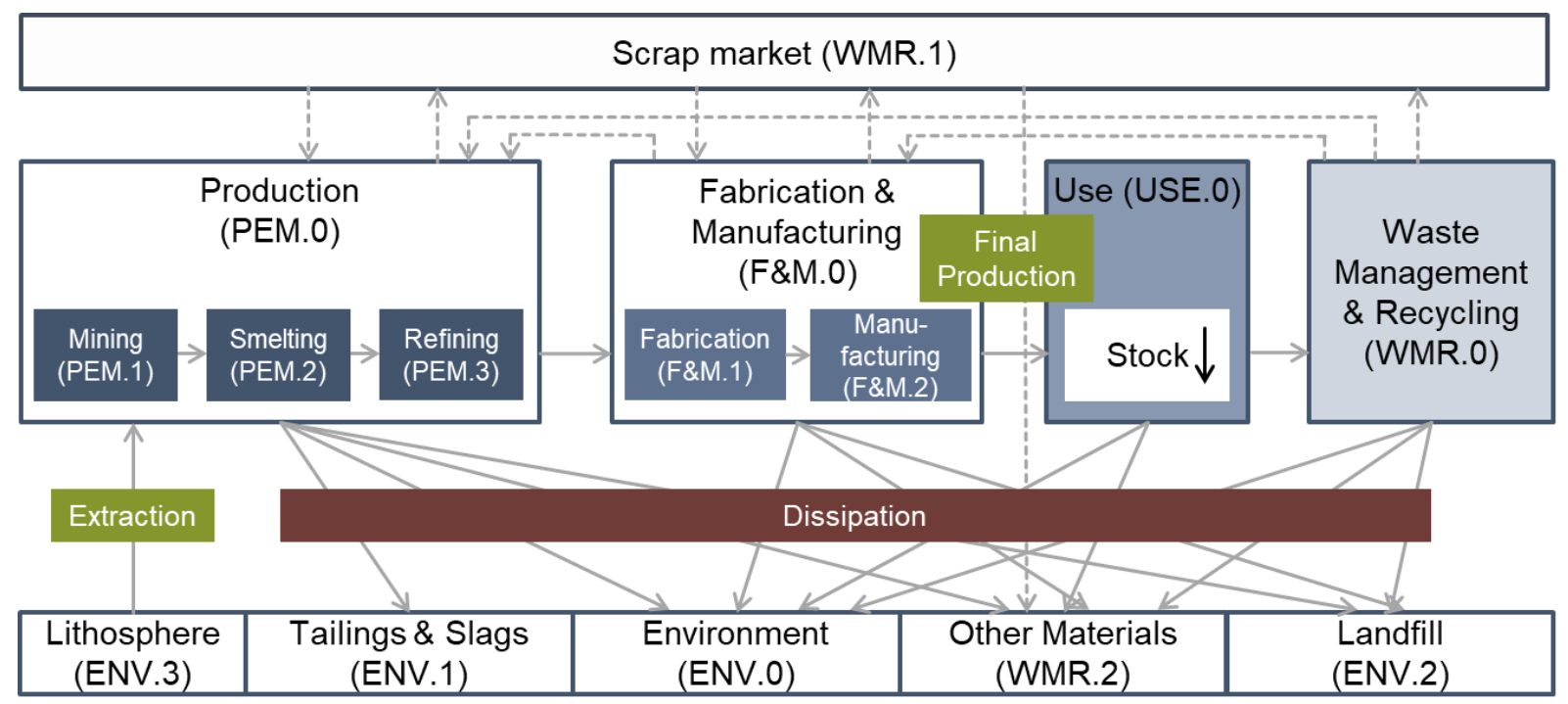

Figure 1: Conceptual model for material flows, stocks and processes in a global mass balance model.

In this article, we identify quantitative indicators for dissipative losses of metals on a global scale including all life cycle stages. The proposed indicators are calculated for a set of 18 metals and metalloids, from now on called metals for simplicity reasons: aluminum, chromium, iron, cobalt, nickel, copper, zinc, gallium, germanium, selenium, silver, indium, tin, tellurium, tantalum, tungsten, rhenium and lead.

In the method section, three indicators for dissipative losses of metals are developed: the two ratios Dissipation-to-Extraction Ratio (DER) and Dissipation-to-Final-Production Ratio (DFR) and additionally the average lifetime of a metal in the anthroposphere $\left(\tau_{A}\right)$. The calculation section describes the data requirements and modelling assumptions. In the results section, the quantified indicators for all 18 metals are presented and compared. The article is finished with a discussion of the results and a conclusion.

\section{Method}

There are two basic approaches for quantifying indicators for dissipative losses on a global scale: either an analysis of mass balances of processes within a specific timeframe or an identification of the fate of a specific material cohort throughout time. Both perspectives utilize the concept of Material Flow Analyses (MFA), either as static mass balance models or as dynamic stock and flow models (Brunner \& Rechberger, 2004).

Global mass balance models, also called static MFAs, can be used to quantify the flows from lithosphere to anthroposphere, called extraction, the flows from fabrication and manufacturing to the use-phase, called final production, and all dissipative losses from all processes (production, fabrication and manufacturing, use-phase, waste management and scrap market).

The first calculated indicator, the Dissipation-to-Extraction Ratio (DER), is the ratio between total dissipative losses and total extracted material within the same timeframe. This timeframe is usually one year. Dissipative losses are more problematic the higher the ratio between dissipation and extraction is. In the end, of course, this ratio cannot be bigger than $100 \%$ except for short-term effects. The main reason why this ratio can be much lower than $100 \%$ is a rapid increase of in-use stocks. Notably, the DER will be close to $100 \%$ for a well-established steady-state circular economy with high recycling rates and low accumulation ratios. 
Postprint Helbig et al. (2020): Resources, Conservation and Recycling 153, 104537

https://doi.org/10.1016/j.resconrec.2019.104537

$$
\text { DER }=\frac{\text { Dissipation }}{\text { Extraction }}
$$

The second indicator, the Dissipation-to-Final-Production Ratio (DFR), is the ratio between total dissipative losses and total material flows entering the use-phase within the same timeframe. As for the DER, this timeframe is usually one year. The material flows entering the use-phase are mainly the final production of metal-containing products as well as material flows included in re-used product. Dissipative losses are more problematic the higher the ratio between dissipation and final production is. This ratio can be bigger than $100 \%$ if there are many dissipative losses from the production or the fabrication \& manufacturing stage.

$$
\text { DFR }=\frac{\text { Dissipation }}{\text { Final Production }+ \text { Re-Use }}
$$

DER and DCR can be quantified for any metal if there is a global mass balance model available that covers all processes from extraction to waste management that makes quantitative statements about dissipative losses.

In contrast to these mass balance models, stock and flow models, also called dynamic MFAs (Müller, Hilty, Widmer, Schluep, \& Faulstich, 2014), show the development of stocks within processes, most importantly the use-phase, and consider lifetime distributions in addition to transfer coefficients. Nakamura and colleagues (Nakamura et al., 2014) developed a dynamic stock model called MaTrace for tracing the fate of materials starting with product use. Their stock modelling needs to be extended with the inclusion of the primary production process to allow a quantification of global dissipative losses over all possible processes. The stocks and flows considered in this model are shown in Figure 2. In particular, the production of end-use products $(x)$, the generation of end-of-life wastes $(z)$, and the in-use stock $(S)$ need to be calculated. It is therefore necessary to estimate the product lifetime distribution $(\phi)$, which is dependent on the product lifetime $(\tau)$ and its standard deviation $(\sigma)$. A higher production yield $(\delta)$ decreases the losses of the production process $\left(\ell_{5}\right)$. A higher fabrication yield $(\lambda)$ and a higher new scrap recovery rate $(\xi)$ both decrease the losses of the manufacturing $\&$ fabrication process $\left(\ell_{4}\right)$. A higher share of dissipative uses $(\omega)$ increases the dissipative losses of the use-phase $\left(\ell_{1}\right)$. A higher collection rate $(\gamma)$ decreases the losses of the waste management process $\left(\ell_{2}\right)$. A higher remelting yield $(\theta)$ decreases the losses in the recycling process $\left(\ell_{3}\right)$. New scrap occurring in the fabrication \& manufacturing process can be collected and remelted without considering product lifetimes, effectively increasing the total available material for fabrication, mathematically covered by a new-scrap recycling loop factor $(\pi)$ (Nakamura et al., 2014). The important measure considered in the third indicator, the Expected Lifetime in the Anthroposphere $\left(\tau_{A}\right)$, is the timing of dissipative losses. Therefore, all dissipative losses at any stage need to be quantified with their specific time delay after extraction. Dissipative losses at the five main processes production, fabrication \& manufacturing, use-phase, waste management and recycling will be considered equally and total dissipative losses $(\ell)$ are the sum of all five processspecific dissipative losses.

$$
\ell(t)=\sum_{i=1}^{5} \ell_{i}(t)
$$

At some point in the future, any utilized material will be dissipated. However, dissipative losses are more problematic for metals with a short expected lifetime in the anthroposphere. The expected lifetime $\left(\tau_{A}\right)$ is calculated as the expected value of the time difference between extraction and dissipation for an average metal cohort. The indicator is similar to the calculation of circularity index by Pauliuk and colleagues (Pauliuk, Kondo, Nakamura, \& Nakajima, 2017) and average lifetime by 
Pauliuk (Pauliuk, 2018), but it includes the losses of primary production before the first use-phase. For that special case, a lifetime of 0 years will be assumed.

$$
\tau_{A}=\lim _{T \rightarrow \infty} \frac{1}{T} \sum_{t=0}^{T} t \frac{\ell(t)}{S(0)+\ell(0)}
$$

The three indicators DER, DCR and $\tau_{A}$ allow an analysis of dissipative losses for any metal. High values of DER and DCR are critical (i.e. problematic) and they indicate how the dissipative material flows are related to intended material flows extraction and utilization. Low values for the expected lifetime are also critical, because they indicate that extracted material is already lost after a short period.

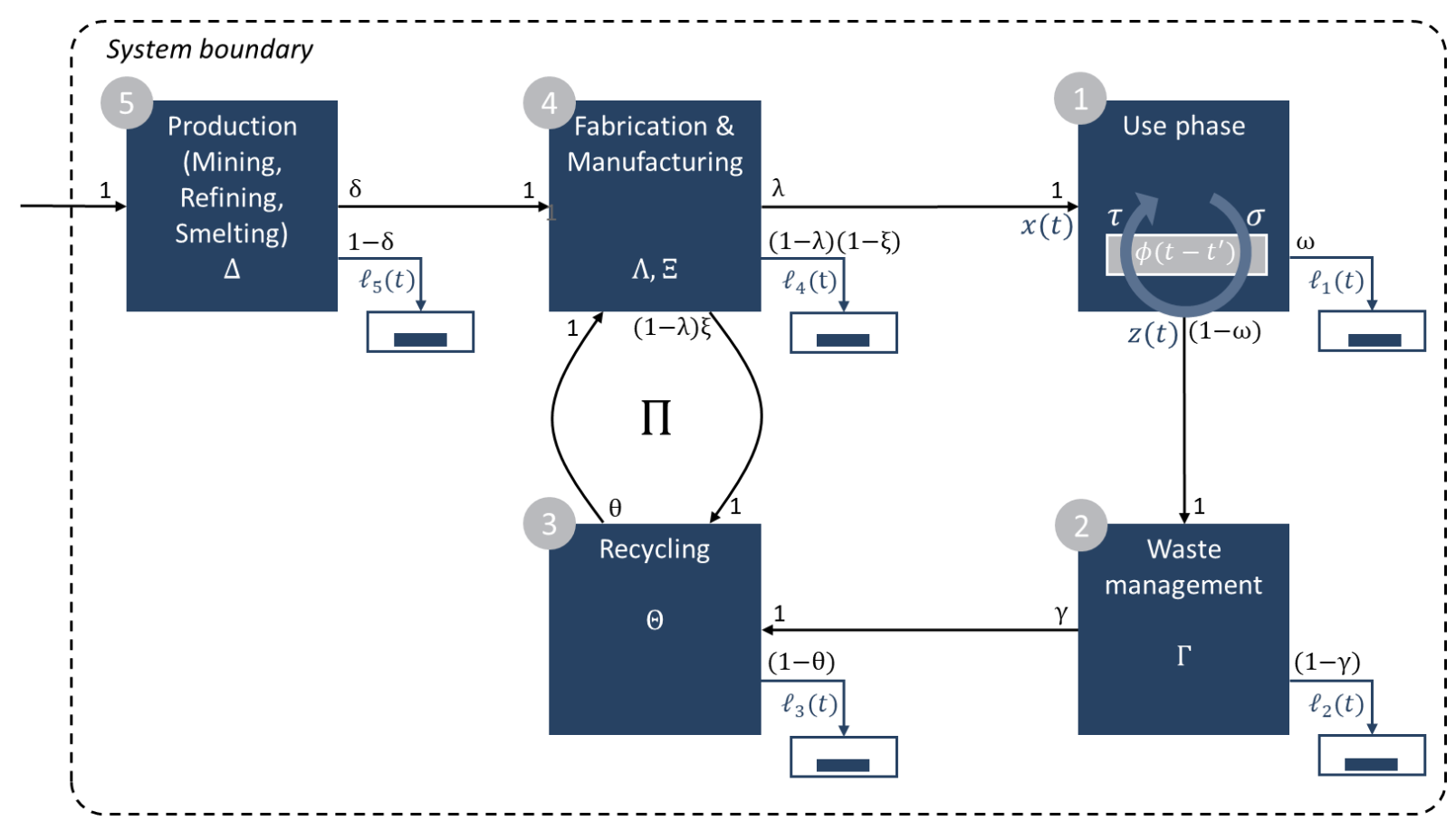

Figure 2: Conceptual model for the transfer coefficients of the dynamic material flow model. $x$ : End-use production. $z$ : End-of-life waste. $\phi$ : Product lifetime distribution. $\tau$ : Average product lifetime. $\sigma$ : Product lifetime deviation. $\delta$ : Production yield. $\lambda$ : Fabrication yield. $\xi$ : New scrap recovery rate. $\omega:$ In-use dissipation rate. $\gamma$ : Collection rate. $\theta$ : Recycling yield.

\section{Calculation}

The basis of the calculation of the three indicators is a detailed analysis of available data for global metal cycles, including all processes from extraction to waste management and including quantitative statements about dissipative losses. The reviews from Chen and Graedel (Chen \& Graedel, 2012) as well as Müller and colleagues (Müller et al., 2014) provide a basis for available MFAs, and are updated with more recently published models. At least one suitable global cycle is available for aluminum (Bertram et al., 2017), chromium (Johnson, Schewel, \& Graedel, 2006), iron (Wang, Müller, \& Graedel, 2007), cobalt (Harper, Kavlak, \& Graedel, 2012), nickel (Reck \& Rotter, 2012), copper (Glöser-Chahoud, 2017), zinc (Meylan \& Reck, 2017), gallium (Licht, Peiró, \& Villalba, 2015), germanium (Licht et al., 2015), selenium (Kavlak \& Graedel, 2013a), silver (Johnson et al., 2005), indium (Licht et al., 2015), tin (Izard \& Müller, 2010), tellurium (Kavlak \& Graedel, 2013b), tantalum (Nedal T. Nassar, 2017), tungsten (Meylan, Reck, \& Graedel, 2015), rhenium (Meylan et al., 2015), and lead (Mao, Dong, \& Graedel, 2008). Despite having a possible data source, the group of rare earth elements is excluded, because the quantitative results from Du and Graedel (Du \& 
Graedel, 2011) are very similar for different rare earth elements and there is too much uncertainty for these data.

Some authors quantify global cycles for different years to show long-term changes in the past (Kavlak \& Graedel, 2013b, 2013a; Nedal T. Nassar, 2017; Reck \& Rotter, 2012). The global tin cycle is based on the period 1927 to 2005 (Izard \& Müller, 2010). The earliest single reference year used in our calculations is 1997 for silver (Johnson et al., 2005), the latest 2015 for tantalum (Nedal T. Nassar, 2017).

The global cycles are analyzed to calculate the indicators DER and DCR for each corresponding reference year. Therefore, the total extracted material, the total final production and the total dissipated material is identified in each corresponding mass balance model. Terminology of processes differ throughout the publications. In order to harmonize terminology, all processes of the evaluated global metal cycles are named and coded closely following the unified materials information system (UMIS) (Myers, Fishman, Reck, \& Graedel, 2019). A list of the used process codes can be found in Table S1 in the Supplementary Material. Extraction is considered any material flow from the lithosphere to the anthroposphere. Final production is any material flow from the fabrication \& manufacturing stage to the use-phase as well as re-use material flows. Dissipation is any material flow into one of the four receiving mediums tailings \& slags, environment, other material flows, and landfills.

The global cycles of metals are additionally analyzed to calculate an estimation for average efficiency parameters: production yield $(\delta)$, fabrication yield $(\lambda)$, new scrap collection rate $(\xi)$, in-use dissipation rate $(\omega)$, old scrap collection rate $(\gamma)$, and remelting yield $(\theta)$. The terminology is consistent with one used by Nakamura and colleagues (Nakamura et al., 2014), except for the addition of the primary production efficiency and the simplification from matrices to scalar values. Table S3 in the Supplementary Material shows the parameters identified from the mass balance models and used for the calculation of each dynamic MFA. Notably, these are average values, and no differences between applications, sectors or production routes are assumed. Secondary and primary material production is assumed to have the same application share. In addition, there are no efficiency increases considered over time, leaving the expected lifetime in the anthroposphere $\left(\tau_{A}\right)$ as a projected value for current efficiencies, not a prognosis.

Every calculation of the expected lifetime starts with 100 units of material entering the use-phase, defined as $x(0)$. In-use dissipation $\left(\ell_{1}\right)$ is allocated to the time of utilization.

$$
\ell_{1}(t)=\omega x(t)
$$

End-of-life waste $(z)$ is defined by previous uses, the in-use dissipation rate and lifetime distribution $(\phi)$.

$$
z(t)=\sum_{t^{\prime}=0}^{t} \phi\left(t-t^{\prime}\right)(1-\omega) x\left(t^{\prime}\right)
$$

In this model, lifetime distributions are estimated as normal distributions in each of the 29 sectors. The sector list can be found in Table S2 in the Supplementary Material. Product lifetimes and standard deviations are listed in Table $\mathrm{S} 4$ in the Supplementary Material. Collection losses $\left(\ell_{2}\right)$ are determined by not properly collected end-of-life wastes.

$$
\ell_{2}(t)=(1-\gamma) z(t)
$$

As fabrication losses are partially collected and remelted, the loop of materials between the fabrication and recycling process needs to be considered. Here, the material available for remelting, and fabrication respectively, is determined by a geometric series of materials entering the recycling 
stage and collected as well as remelted fabrication losses. The limit of this geometric series will be called new-scrap recycling loop factor $\pi$.

$$
1+\theta \xi(1-\lambda)+\cdots+(\theta \xi(1-\lambda))^{n} \stackrel{n \rightarrow \infty}{\longrightarrow}(1-\theta \xi(1-\lambda))^{-1}=: \pi
$$

The input into the fabrication stage required to produce $x(0)$ is $X_{54}(0)=\pi^{-1} \lambda^{-1} x(0)$. Primary production in this model is only necessary in the initial period. Afterwards, no primary production is considered anymore and consequently no additional production losses occur anymore: $\ell_{5}(t>0)=$ 0 . Losses from primary production therefore also only occur in the first calculated period.

$$
\ell_{5}(0)=(1-\delta) \delta^{-1} \pi^{-1} \lambda^{-1} x(0)
$$

Remelting losses are losses in the recycling process, applied to collected new and old scrap material flows. Collected old scrap flows $\left(X_{23}\right)$ are calculated as $X_{23}(t)=\gamma z(t)$. Collected new scrap material flows are calculated for the initial period as $X_{43}(0)=\xi(1-\lambda) \pi X_{54}(0)$ and afterwards as $X_{43}(t>0)=\xi(1-\lambda) \theta \pi X_{23}(t>0)$.

$$
\ell_{3}(t)=(1-\theta)\left(X_{23}(t)+X_{43}(t)\right)
$$

Fabrication losses are losses in the fabrication process, for which again primary production is considered in the initial phase only and remelted new scrap material flows are calculated for the initial period as $X_{34}(0)=\theta \xi(1-\lambda) \pi X_{54}(0)$ and afterwards as $X_{34}(t>0)=\theta \pi X_{23}(t>0)$.

$$
\ell_{4}(t)=(1-\xi)(1-\lambda)\left(X_{54}(t)+X_{34}(t)\right)
$$

The calculations for the stock and flow model are run with a value of $T=1000$, meaning that a thousand discrete years are calculated.

\section{Results}

The analysis of global cycles and harmonized yield parameters for each of the metals gives quantitative results for the three indicators DER, DCR, and $\tau_{A}$. Additionally, a harmonized mass balance diagram as well as the development of modeled in-use stocks and dissipative losses can be displayed. These are in total 36 figures for 18 metals. Therefore, here only the results for aluminum and indium are shown and discussed. Additional information to the underlying mass balance models and all graphs are shown in Figures S1 to S36 in the Supplementary Material. Numerical results for 1000 years for all metals are also available in Table S5 in the Supplementary Material. Mass balance diagrams are created with the STAN software (version 2.6.801) (Cencic \& Rechberger, 2008). Stock development graphs are created with a Python (version 3.7) algorithm, partially based on the MaTrace-global model (Pauliuk et al., 2017).

Figure 3a displays the global mass flows for aluminum in the year 2014, according to the model from Bertram and colleagues (Bertram et al., 2017). Substantial insights gained from this display are the rapid increase of in-use stocks (+46 Mt or $46 \mathrm{Tg}$ in 2014), the high share of new scraps among all recycled materials and the fact that final production material flows (65 Mt) are already bigger than extraction (63 Mt). Aluminum is mostly used in the form of various wrought and cast alloys. It is known that wrought aluminum often gets recycled as cast aluminum, with inherently different properties and applications (Cullen \& Allwood, 2013). The main applications for aluminum are the transport sector, construction, packaging material and infrastructure. Packaging materials have a very short lifetime, modeled here with just 1 year, whereas construction materials are considered to have a product lifetime of 50 years. Since only applications as reducing agents are considered as unrecyclable and since the yields throughout the aluminum cycle are comparatively high (see Table S2 in the Supplementary Material), the expected lifetime of aluminum of 98 years is the second highest among the 18 selected metals. Figure 4a displays the development of in-use stocks and cumulative dissipative losses over two centuries. In-use dissipation can be neglected for the case of 
aluminum. After 200 years, the most important dissipative loss for the aluminum cohort comes from collection losses. Production, fabrication and remelting losses contribute equally to the remaining dissipation.
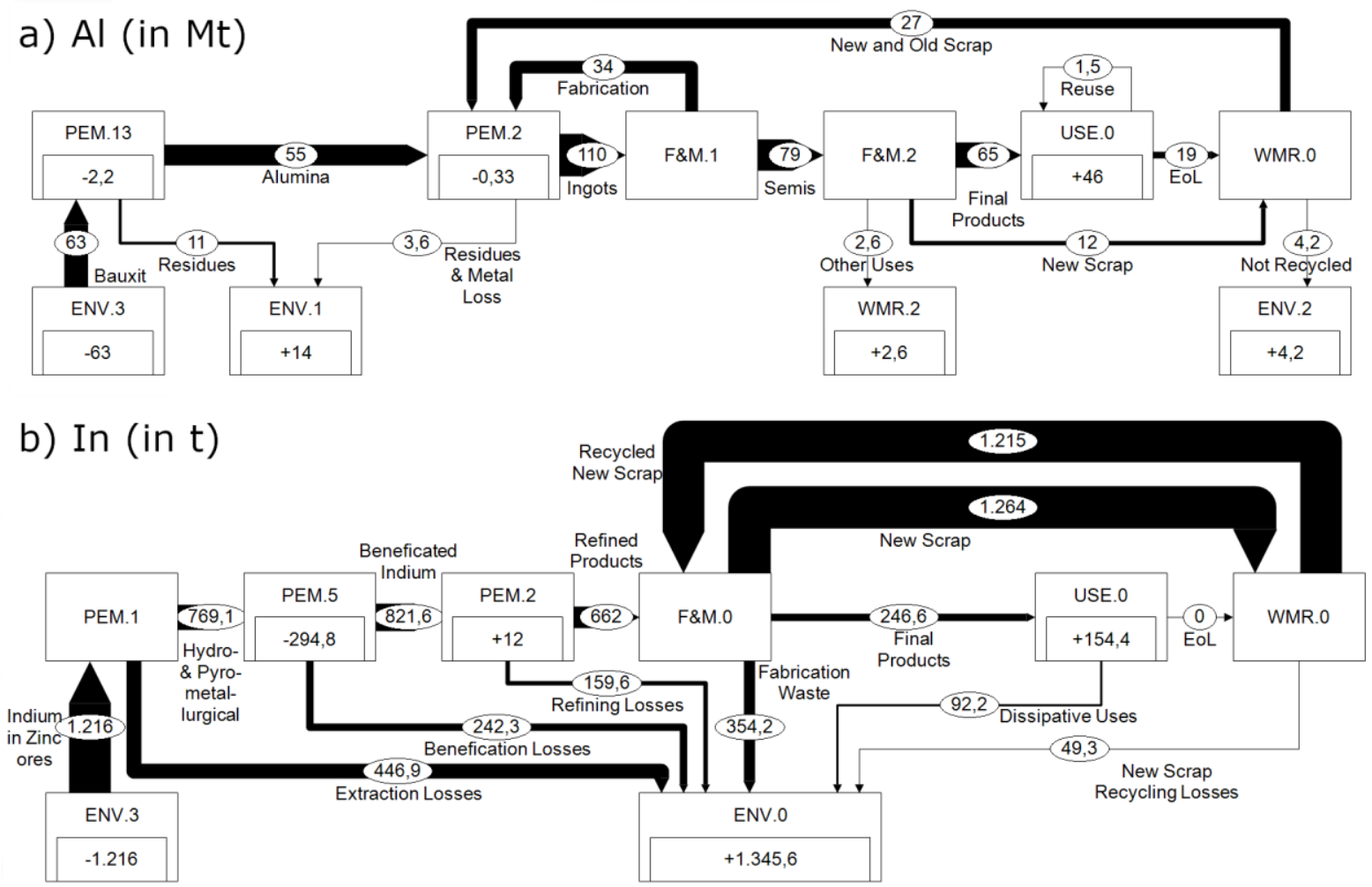

Figure 3: Global mass flows for aluminum (Figure 3a) in year 2014 in Mt (1 megaton $=10^{9} \mathrm{~kg}$ ) and indium (Figure 3b) in year 2011 in t (1 metric ton $=10^{3} \mathrm{~kg}$ ). Data from Betram et al. (Bertram et al., 2017) and Licht et al. (Licht et al., 2015). PEM: Production of extraction materials. F\&M: Fabrication \& manufacturing. USE: Usephase. WMR: Waste management \& recycling. ENV: Environment. Abbreviations for individual processes are listed in Table S1 in the Supplementary Material.

Figure $3 \mathrm{~b}$ displays the global mass flows for indium in the year 2011, according to the model from Licht and colleagues (Licht et al., 2015). Here, the biggest material flows are interestingly new scrap material flows $(1,264 \mathrm{t})$, predominantly from indium-tin-oxide fabrication processes. Indium is also a by-product of zinc mining, resulting in relatively high losses from the primary production stage. Despite high remelting rates of collected new scraps, the fabrication losses are the second most important source of dissipative losses for indium. Only $247 \mathrm{t}$ of indium are included in new end-use products. End-of-life wastes are so far not important; end-of-life recycling is consequentially not contributing to secondary production. Indium is mostly used in electronic products and some alloys. Because of the large amount of losses occurring during the production and fabrication stage as well as the modeled lifetime of 13.4 years for electronics, indium is on spectrum of short-lived metals in the anthroposphere. Figure $4 \mathrm{~b}$ shows the development of in-use stocks and dissipative losses of an indium cohort over 200 years. After this period, production losses and fabrication losses are still the most important source of dissipative losses for one used indium cohort, followed by collection losses and in-use dissipation. The expected lifetime in the anthroposphere is only about 3 years. 

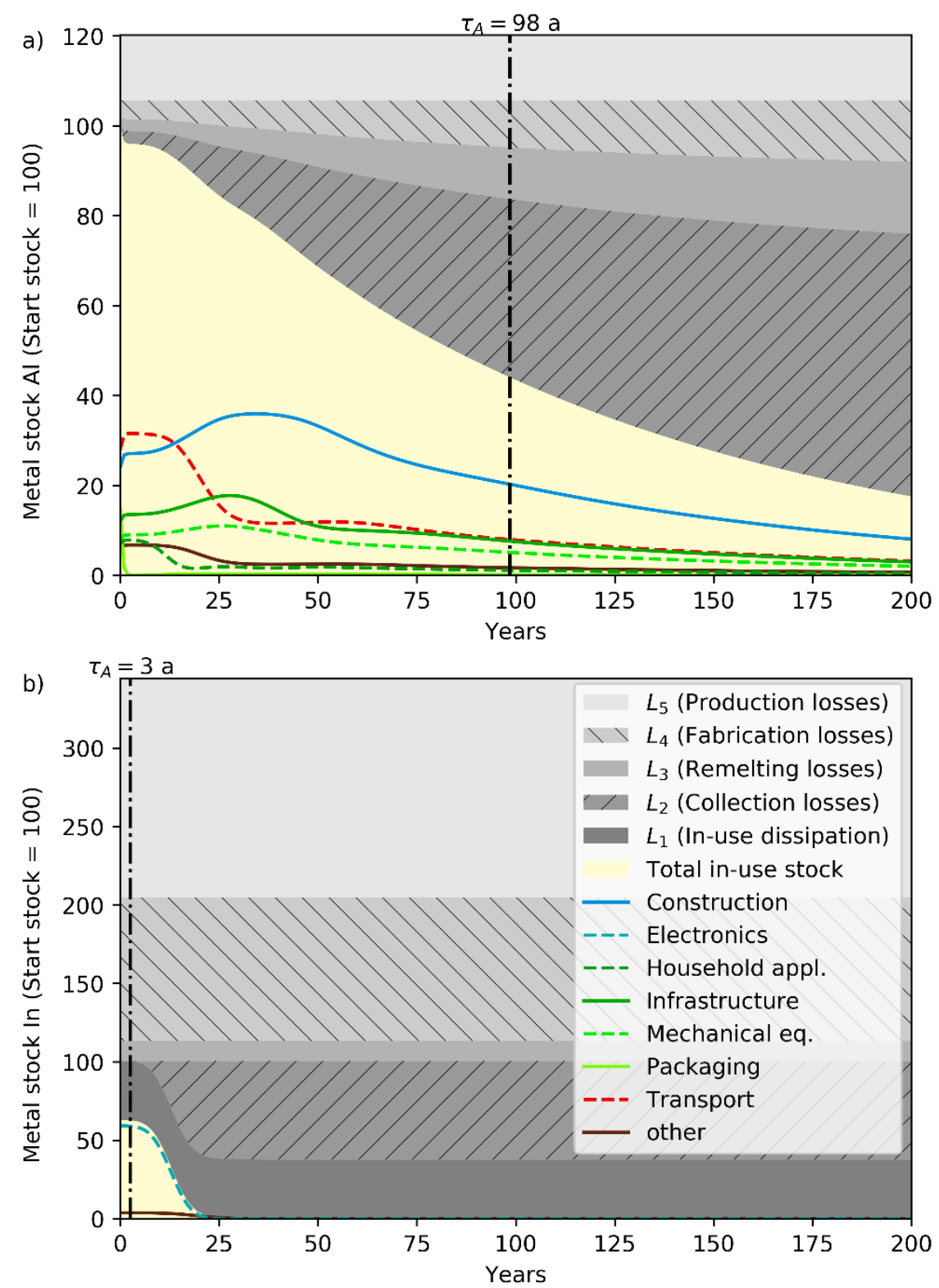

Figure 4: Aluminum (a) and indium (b) in in-use stocks and development of cumulative dissipative losses, projected for 200 years based on current global process yields. Vertical dashed-dotted line indicates the expected lifetime of aluminum and indium in the anthroposphere.

Both aluminum and indium are metals with rapid growth in global use and both have established recycling systems, in particular for new scraps. Nevertheless, the two metals have contrasting patterns when it comes to the analysis of dissipative losses. Aluminum has many different applications, while indium in-use stocks are mostly in the electronics sector. Aluminum dissipative losses can best be reduced by higher collection yields; indium needs better by-product separation and lower fabrication losses. Aluminum stays in the anthroposphere after extraction for almost a century, whereas indium on average is already lost already after a few years. 
Postprint Helbig et al. (2020): Resources, Conservation and Recycling 153, 104537

https://doi.org/10.1016/j.resconrec.2019.104537

Table 1: Key values of global cycles of 18 metals according to their mass balance models and the stock and flow model for the expected lifetime. Mass units given in metric tons $\left(1 \mathrm{t}=10^{3} \mathrm{~kg}\right)$

\begin{tabular}{|c|c|c|c|c|c|c|c|c|}
\hline Element & Extraction & Final Production & Dissipation & $\Delta$ Stock & DER & DCR & $\tau_{A}$ & Ref. year \\
\hline $\mathrm{Al}$ & $63.0 \mathrm{Mt}$ & $66.5 \mathrm{Mt}$ & $21.4 \mathrm{Mt}$ & $43.5 \mathrm{Mt}$ & $34 \%$ & $32 \%$ & $98 \mathrm{a}$ & 2014 \\
\hline $\mathrm{Cr}$ & $5.14 \mathrm{Mt}$ & $3.32 \mathrm{Mt}$ & $2.63 \mathrm{Mt}$ & $2.51 \mathrm{Mt}$ & $51 \%$ & $79 \%$ & $32 \mathrm{a}$ & 2000 \\
\hline $\mathrm{Fe}$ & $694 \mathrm{Mt}$ & $746 \mathrm{Mt}$ & $212 \mathrm{Mt}$ & $482 \mathrm{Mt}$ & $31 \%$ & $28 \%$ & $110 \mathrm{a}$ & 2000 \\
\hline Co & $127 \mathrm{kt}$ & $53.2 \mathrm{kt}$ & $114 \mathrm{kt}$ & $12.4 \mathrm{kt}$ & $90 \%$ & $214 \%$ & $3 a$ & 2005 \\
\hline $\mathrm{Ni}$ & $1.58 \mathrm{Mt}$ & $1.57 \mathrm{Mt}$ & $559 \mathrm{kt}$ & $920 \mathrm{kt}$ & $35 \%$ & $36 \%$ & $58 \mathrm{a}$ & 2005 \\
\hline $\mathrm{Cu}$ & $19.8 \mathrm{Mt}$ & $20.9 \mathrm{Mt}$ & 10.6 Mt & $9.20 \mathrm{Mt}$ & $54 \%$ & $51 \%$ & $45 a$ & 2011 \\
\hline $\mathrm{Zn}$ & $14.0 \mathrm{Mt}$ & $13.0 \mathrm{Mt}$ & $9.38 \mathrm{Mt}$ & $4.50 \mathrm{Mt}$ & $67 \%$ & $72 \%$ & $16 a$ & 2010 \\
\hline $\mathrm{Ga}$ & $21.0 \mathrm{kt}$ & $178 \mathrm{t}$ & $20.9 \mathrm{kt}$ & $91.2 \mathrm{t}$ & $100 \%$ & $11747 \%$ & 1 month & 2011 \\
\hline $\mathrm{Ge}$ & $12.6 \mathrm{kt}$ & $49 t$ & $12.5 \mathrm{kt}$ & $23.5 t$ & $100 \%$ & $25581 \%$ & 1 month & 2011 \\
\hline Se & $53.8 \mathrm{kt}$ & $2.25 \mathrm{kt}$ & $53.8 \mathrm{kt}$ & $20.0 \mathrm{t}$ & $100 \%$ & $2390 \%$ & 6 months & 2020 \\
\hline $\mathrm{Ag}$ & $20.2 \mathrm{kt}$ & $26.8 \mathrm{kt}$ & $11.5 \mathrm{kt}$ & $8.70 \mathrm{kt}$ & $57 \%$ & $43 \%$ & $40 a$ & 1997 \\
\hline In & $1.22 \mathrm{kt}$ & $247 \mathrm{t}$ & $1.35 \mathrm{kt}$ & $-128 t$ & $111 \%$ & $546 \%$ & $3 a$ & 2011 \\
\hline Sn & $17.0 \mathrm{Mt}$ & $18.6 \mathrm{Mt}$ & $15.9 \mathrm{Mt}$ & $1.55 \mathrm{Mt}$ & $94 \%$ & $86 \%$ & $11 \mathrm{a}$ & 1927-2005 \\
\hline Te & $11.1 \mathrm{kt}$ & $390 t$ & $10.9 \mathrm{kt}$ & $250 \mathrm{t}$ & $98 \%$ & $2785 \%$ & 9 months & 2010 \\
\hline $\mathrm{Ta}$ & $2.42 \mathrm{kt}$ & $1.47 \mathrm{kt}$ & $2.17 \mathrm{kt}$ & $140 t$ & $90 \%$ & $148 \%$ & $8 a$ & 2015 \\
\hline W & 51.0 kt & 56.0 kt & $47.0 \mathrm{kt}$ & $5.00 \mathrm{kt}$ & $92 \%$ & $84 \%$ & $5 a$ & 2008 \\
\hline $\operatorname{Re}$ & $120 t$ & $70 t$ & $78 \mathrm{t}$ & $42 \mathrm{t}$ & $65 \%$ & $111 \%$ & $13 \mathrm{a}$ & 2008 \\
\hline $\mathrm{Pb}$ & $3.50 \mathrm{Mt}$ & $5.93 \mathrm{Mt}$ & $2.84 \mathrm{Mt}$ & $6.63 \mathrm{Mt}$ & $81 \%$ & $48 \%$ & $14 \mathrm{a}$ & 2000 \\
\hline
\end{tabular}

Table 1 shows the key values and results of all 18 metal cycles and the reference year of each quantitatively evaluated metal cycle. The material flows of the 18 metals differ in six orders of magnitude. While $694 \mathrm{Mt}\left(=10^{9} \mathrm{~kg}\right)$ of iron are extracted and $746 \mathrm{Mt}$ of iron are utilized according to Wang and colleagues every year (Wang et al., 2007), the respective values for rhenium are only $120 \mathrm{t}$ of extraction and $70 \mathrm{t}$ of utilization (Meylan et al., 2015). Total dissipative losses therefore differ between $212 \mathrm{Mt}$ for iron and $78 \mathrm{t}$ for rhenium. Stock change are smallest for rhenium with $42 \mathrm{t}$ and biggest for iron with $482 \mathrm{Mt}$. Indium stock change was estimated to be negative for year 2011 because of an increased processing of previously stockpiled zinc residues (Licht et al., 2015). This negative stock change is also the reason for the DER above $100 \%$ of indium. The Dissipation-toExtraction Ratio (DER) is the highest for $\mathrm{Ga}, \mathrm{Ge}$, Se, and In, with basically the same dissipative losses as extracted material. The lowest values for DER are observed for $\mathrm{Al}, \mathrm{Fe}$, and $\mathrm{Ni}$. For these metals, extraction material flows are about three times as big as dissipative losses. The Dissipation-to-FinalProduction Ratio (DFR) is the highest for $\mathrm{Ga}, \mathrm{Ge}, \mathrm{Se}$, and Te, for each of which 24 to 256 times as many dissipative losses occur than there are material inputs to the use-phase. The lowest values for $\mathrm{DCR}$ are again observed for $\mathrm{Al}, \mathrm{Fe}$, and $\mathrm{Ni}$, for which they are very close to the calculated DER. The expected lifetime is below one year for the metals $\mathrm{Ga}, \mathrm{Ge}, \mathrm{Se}$, and Te. The longest lifetimes have, once again, $\mathrm{Al}, \mathrm{Fe}$, and $\mathrm{Ni}$. Figure 5 shows the results for the three indicators DER, DCR and $\tau_{A}$ for all 18 metals in a scatter plot. Metals are most critical if they are in the top left corner of the graph and least critical if they appear in the bottom right corner of the graph. 


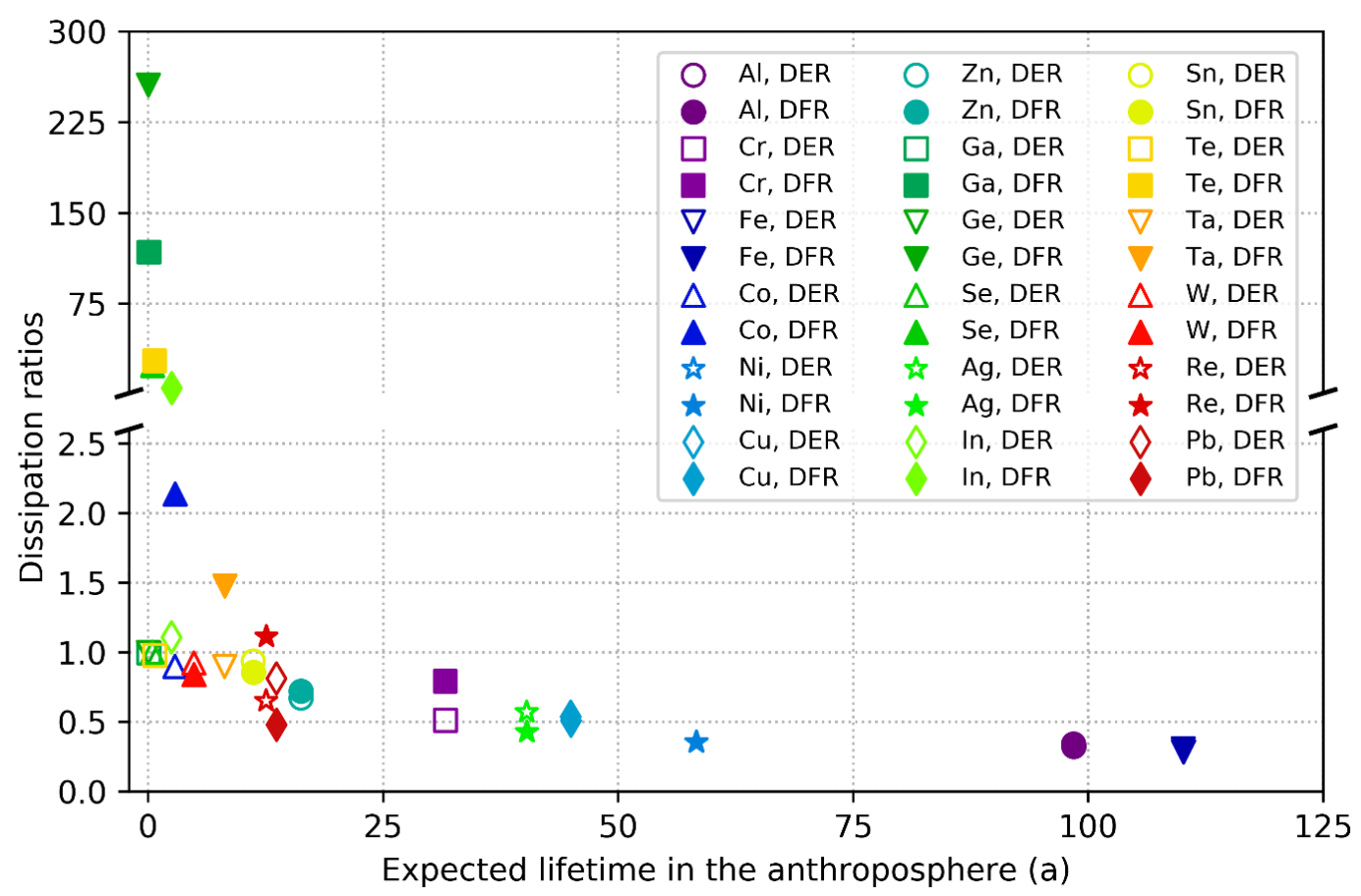

Figure 5: Dissipation-to-Extraction Ratio (DER), Dissipation-to-Final-Production Ratio (DCR), and expected lifetime in the anthroposphere $\left(\tau_{A}\right)$ as a scatter plot. Ordinate is broken at a value of 3.

\section{Discussion}

It is important to note that the total dissipative losses calculated for all three indicators do not differentiate between receiving mediums. All receiving mediums are considered equally important, because recovery is impossible for all of them given current technological and economic conditions. It can be argued that dissipation to the environment is worst because material is mobilized and has potential for environmental damage (Zimmermann \& Gößling-Reisemann, 2013). However, even global mass balance studies making quantitative statements about dissipative losses are predominantly vague about the receiving mediums. For example, Licht and colleagues (Licht et al., 2015) consider all dissipative losses as losses to the environment, which differs from most other models and is therefore questionable. On the contrary, as an example, Nakamura and colleagues (Nakamura, Kondo, Nakajima, Ohno, \& Pauliuk, 2017) describe that chromium during steel recycling may become a dissipative loss to the slag whereas nickel in the same process is lost as dissipation into carbon steels without functional advantages. For the potentially hazardous lead, Mao and colleagues (Mao, Cao, \& Graedel, 2009) even quantify dissipative losses into different compartments of the environment, making this another good example for explicit consideration of receiving mediums.

The inclusion of technical and economic criteria into the definition of the term dissipative losses by Zimmermann and Gößling-Reisemann (Zimmermann \& Gößling-Reisemann, 2013) means that this definition is per se time-dependent. It is debatable whether tailings and slags or landfills should be considered final deposits for dissipated materials. Ongoing research examines the potential of tailings, e.g. for the recovery of indium (Werner, Ciacci, Mudd, Reck, \& Northey, 2018), and landfills as future resources (Winterstetter, Laner, Rechberger, \& Fellner, 2015). However, currently in the vast majority of these cases, these stocks are considered technically and economically unrecoverable and therefore material flows into these receiving mediums are considered dissipative losses. 
The dynamic stock model does not differentiate between different applications of one metal, scrap types or production routes (including primary and secondary production). This rather strong assumption is particularly important for aluminum and steel markets. Steel markets can be differentiated along the two production routes of blast oxygen furnace and electric arc furnace. Steel is usually recycled in the electric production route. The implications of different recycling routes and production allocation on dynamic stock models at the example of steel is shown by Pauliuk and colleagues (Pauliuk et al., 2017). It is also easier to recycle aluminum alloys into cast alloys, because of generally higher share of alloying elements in cast aluminum. A possible extension of the expected lifetime model could include the measurement of maintained quality of a material throughout its life cycle. The term quality however always needs an application context and is difficult to define generally. Therefore, thermodynamic properties, functionality of the material and commodity prices can be used for quality estimation. However, because many of the underlying global cycles do not allow the identification of product- or technology-specific parametrization, the same yet high level of aggregation is chosen of the dynamic stock model.

Measures to reduce the amount of dissipative losses across all metals encompass goals for waste collection and recycling, material efficiency, waste storing, eco-design, more efficient recycling technologies, by-product separation, markets for recycled materials and recycling incentives for the industry (Ayres \& Peiró, 2013; Ciacci et al., 2015; Kral, Kellner, \& Brunner, 2013; Leal-Ayala, Allwood, Petavratzi, Brown, \& Gunn, 2015; Nakamura et al., 2017; Zimmermann, 2015, 2017). Overall, eight goals for avoiding dissipative losses can be named, distributed among the five modeled processes. For production, higher yields and better by-product separation are desirable. Higher fabrication yields and remelting yields will have rebound effects on the primary production requirements. Waste collection needs to be increased for both old and new scrap, with old scrap having the additional challenge of achieving higher sorting rates. Technological options for improving sorting and remelting at the example of aluminum are described by Gaustad and colleagues (Gaustad, Olivetti, \& Kirchain, 2012). For the case of WEEE, de Meester and colleagues identify changes to consumer behavior and better separation technologies as the main factors on environmental impact (De Meester, Nachtergaele, Debaveye, Vos, \& Dewulf, 2019). Dissipative uses should be avoided whenever possible and substitution with less critical and less dissipative materials should be considered (Helbig, 2019).

Dissipative losses are also growing in interest for the scientific community of Life Cycle Impact Assessment (LCIA) (Zampori \& Sala, 2017). The presented indicators are not yet fully applicable as impact factors in the LCA framework. However, the dynamic MFAs used for the calculation of the expected lifetime in the anthroposphere can be adapted to calculate such impact factors.

Indicators for dissipative losses may also be applied in criticality assessments in a dissipation dimension in addition to the supply risk dimension. If dissipative losses and supply risks of metals are high, the material is critical both at the beginning and at the end of its life cycle. The comparison of dissipation indicators with the Augsburg method of supply risks assessments (Kolotzek, Helbig, Thorenz, Reller, \& Tuma, 2018) showed that cobalt, selenium and indium have both high supply risks and dissipative losses (Helbig, 2019). Aluminum, iron and copper, on the contrary, show relatively low supply risks as well as dissipative losses.

\section{Conclusions}

The phenomenon of dissipative losses of metals shows different patterns throughout the periodic table. Dissipative losses are unrecoverable material flows into receiving mediums like tailings \& slags, 
environment, landfills, or other material flows. They are more important for quantifying material consumption of metals than extraction. Three indicators can be used to analyze dissipative losses of metals quantitatively: the Dissipation-to-Extraction Ratio (DER), the Dissipation-to-Final-Production Ratio (DFR), and the expected lifetime in the anthroposphere $\left(\tau_{A}\right)$.

Despite all recycling efforts, even for mass metals like aluminum and iron, about a third of the extracted and used materials is lost every year as dissipation. For technology metals like gallium and germanium, the dissipative losses can be a many times higher than the material utilization in end-use products. The expected lifetime of metals in the anthroposphere, starting with extraction, can be only a few months for some technology metals. For aluminum and iron, this lifetime is about a century, and therefore much less critical.

Dissipative losses can be reduced through higher production, fabrication, collection and remelting yields, but also through avoiding dissipative uses of metals. Avoiding dissipative losses decreases the need for mining, resulting in reduced supply risks and reduced environmental impact from primary production.

The three indicators can be calculated given there are sufficient data about global metal cycles from mining to landfilling including information about dissipative losses in each of the processes. These data are currently available for the analyzed 18 metals in this article. In addition to expanding the understanding of global metal cycles of other metals, future research may focus on increasing the resolution of underlying material flow models with regional and sector specific parameters.

\section{Acknowledgements}

The quantitative model used in the manuscript is based on the dissertation of Christoph Helbig, which is published in German at the University of Augsburg. We thank Armin Reller, Alex Bradshaw and Alois Loidl for supervising and commenting the thesis.

We thank Matthias Aigner for his support on editing the Supplementary Material.

We thank Stefanie Klose for commenting on dynamic stock figures at the ISIE SEM Conference 2019 in Berlin.

\section{Supplementary Material}

Additional information can be found in two Supplementary Materials.

\section{Declarations of interest}

None. 


\section{References}

Ayres, R. U., \& Peiró, L. T. (2013). Material efficiency: rare and critical metals. Philosophical Transactions of the Royal Society A: Mathematical, Physical and Engineering Sciences, 371, 20110563. https://doi.org/10.1098/rsta.2011.0563

Bertram, M., Ramkumar, S., Rechberger, H., Rombach, G., Bayliss, C., Martchek, K. J., ... Liu, G. (2017). A regionally-linked, dynamic material flow modelling tool for rolled, extruded and cast aluminium products. Resources, Conservation and Recycling, 125, 48-69. https://doi.org/10.1016/j.resconrec.2017.05.014

Brunner, P. H., \& Rechberger, H. (2004). Practical Handbook of Material Flow Analysis. Lewis Publishers.

Cencic, O., \& Rechberger, H. (2008). Material Flow Analysis with Software STAN. Envirolnfo 2008 Environmental Informatics and Industrial Ecology, 2008, 440-447.

Chen, W.-Q., \& Graedel, T. E. (2012). Anthropogenic Cycles of the Elements: A Critical Review. Environmental Science \& Technology, 46(16), 8574-8586. https://doi.org/10.1021/es3010333

Ciacci, L., Harper, E. M., Nassar, N. T., Reck, B. K., \& Graedel, T. E. (2016). Metal Dissipation and Inefficient Recycling Intensify Climate Forcing. Environmental Science \& Technology, 50(20), 11394-11402. https://doi.org/10.1021/acs.est.6b02714

Ciacci, L., Reck, B. K., Nassar, N. T., \& Graedel, T. E. (2015). Lost by Design. Environmental Science \& Technology, 49(16), 9443-9451. https://doi.org/10.1021/es505515z

Cullen, J. M., \& Allwood, J. M. (2013). Mapping the Global Flow of Aluminum: From Liquid Aluminum to End-Use Goods. Environmental Science \& Technology, 47(7), 130311125652007. https://doi.org/10.1021/es304256s

De Meester, S., Nachtergaele, P., Debaveye, S., Vos, P., \& Dewulf, J. (2019). Using material flow analysis and life cycle assessment in decision support: A case study on WEEE valorization in Belgium. Resources, Conservation and Recycling, 142(July 2018), 1-9. https://doi.org/10.1016/j.resconrec.2018.10.015

Du, X., \& Graedel, T. E. (2011). Uncovering the Global Life Cycles of the Rare Earth Elements. Scientific Reports, 1(1), 145. https://doi.org/10.1038/srep00145

Gaustad, G., Olivetti, E., \& Kirchain, R. (2012). Improving aluminum recycling: A survey of sorting and impurity removal technologies. Resources, Conservation and Recycling, 58, 79-87. https://doi.org/10.1016/j.resconrec.2011.10.010

Glöser-Chahoud, S. (2017). Quantitative Analyse der Kritikalität mineralischer und metallischer Rohstoffe unter Verwendung eines systemdynamischen Modell-Ansatzes (TU Clausthal). https://doi.org/10.21268/20170724-133145

Graedel, T E, Harper, E. M., Nassar, N. T., \& Reck, B. K. (2015). On the materials basis of modern society. Proceedings of the National Academy of Sciences, 112(20), 6295-6300. https://doi.org/10.1073/pnas.1312752110

Harper, E. M., Kavlak, G., \& Graedel, T. E. (2012). Tracking the metal of the goblins: Cobalt's cycle of use. Environmental Science \& Technology, 46(2), 1079-1086. https://doi.org/10.1021/es201874e

Helbig, C. (2019). Metalle im Spannungsfeld technoökonomischen Handelns: Eine Bewertung der Versorgungsrisiken mit Methoden der Industrial Ecology. Universität Augsburg.

Izard, C. F., \& Müller, D. B. (2010). Tracking the devil's metal: Historical global and contemporary U.S. tin cycles. Resources, Conservation and Recycling, 54(12), 1436-1441. https://doi.org/10.1016/j.resconrec.2010.06.008

Johnson, J. X., Jirikowic, J., Bertram, M., van Beers, D., Gordon, R. B., Henderson, K., ... Graedel, T. E. (2005). Contemporary Anthropogenic Silver Cycle: A Multilevel Analysis. Environmental Science \& Technology, 39(12), 4655-4665. https://doi.org/10.1021/es048319x

Johnson, J. X., Schewel, L., \& Graedel, T. E. (2006). The contemporary anthropogenic chromium cycle. Environmental Science and Technology, 40(22), 7060-7069. https://doi.org/10.1021/es060061i

Kavlak, G., \& Graedel, T. E. (2013a). Global anthropogenic selenium cycles for 1940-2010. Resources, Conservation and Recycling, 73, 17-22. https://doi.org/10.1016/j.resconrec.2013.01.013 
Kavlak, G., \& Graedel, T. E. (2013b). Global anthropogenic tellurium cycles for 1940-2010. Resources Conservation and Recycling, 76, 21-26. https://doi.org/10.1016/j.resconrec.2013.04.007

Kolotzek, C., Helbig, C., Thorenz, A., Reller, A., \& Tuma, A. (2018). A company-oriented model for the assessment of raw material supply risks, environmental impact and social implications. Journal of Cleaner Production, 176, 566-580. https://doi.org/10.1016/j.jclepro.2017.12.162

Kral, U., Kellner, K., \& Brunner, P. H. (2013). Sustainable resource use requires "clean cycles" and safe "final sinks." Science of The Total Environment, 461-462, 819-822. https://doi.org/10.1016/j.scitotenv.2012.08.094

Leal-Ayala, D. R., Allwood, J. M., Petavratzi, E., Brown, T. J., \& Gunn, G. (2015). Mapping the global flow of tungsten to identify key material efficiency and supply security opportunities. Resources, Conservation and Recycling, 103, 19-28. https://doi.org/10.1016/j.resconrec.2015.07.003

Licht, C., Peiró, L. T., \& Villalba, G. (2015). Global Substance Flow Analysis of Gallium, Germanium, and Indium: Quantification of Extraction, Uses, and Dissipative Losses within their Anthropogenic Cycles. Journal of Industrial Ecology, 19(5), 890-903. https://doi.org/10.1111/jiec.12287

Lifset, R. J., Eckelman, M. J., Harper, E. M., Hausfather, Z., \& Urbina, G. (2012). Metal lost and found: Dissipative uses and releases of copper in the United States 1975-2000. Science of the Total Environment, 417, 138-147. https://doi.org/10.1016/j.scitotenv.2011.09.075

Mao, J., Cao, J., \& Graedel, T. E. (2009). Losses to the environment from the multilevel cycle of anthropogenic lead. Environmental Pollution, 157(10), 2670-2677. https://doi.org/10.1016/j.envpol.2009.05.003

Mao, J., Dong, J., \& Graedel, T. E. (2008). The multilevel cycle of anthropogenic lead. II. Results and discussion. Resources, Conservation and Recycling, 52(8-9), 1050-1057. https://doi.org/10.1016/j.resconrec.2008.04.005

Meylan, G., \& Reck, B. K. (2017). The anthropogenic cycle of zinc: Status quo and perspectives. Resources, Conservation and Recycling, 123, 1-10. https://doi.org/10.1016/j.resconrec.2016.01.006

Meylan, G., Reck, B. K., \& Graedel, T. E. (2015). Comprehensive Global and United States Cycles of Gallium, Germanium, Rhenium, and Tungsten in 2008: Final report on USGS Research Grant G14AP00059.

Müller, E., Hilty, L. M., Widmer, R., Schluep, M., \& Faulstich, M. (2014). Modeling metal stocks and flows: A review of dynamic material flow analysis methods. Environmental Science and Technology, 48(4), 2102-2113. https://doi.org/10.1021/es403506a

Myers, R. J., Fishman, T., Reck, B. K., \& Graedel, T. E. (2019). Unified Materials Information System (UMIS): An Integrated Material Stocks and Flows Data Structure. Journal of Industrial Ecology, 23(1), 222-240. https://doi.org/10.1111/jiec.12730

Nakamura, S., Kondo, Y., Kagawa, S., Matsubae, K., Nakajima, K., \& Nagasaka, T. (2014). MaTrace: Tracing the Fate of Materials over Time and Across Products in Open-Loop Recycling. Environmental Science \& Technology, 48(13), 7207-7214. https://doi.org/10.1021/es500820h

Nakamura, S., Kondo, Y., Nakajima, K., Ohno, H., \& Pauliuk, S. (2017). Quantifying Recycling and Losses of $\mathrm{Cr}$ and $\mathrm{Ni}$ in Steel Throughout Multiple Life Cycles Using MaTrace-Alloy. Environmental Science \& Technology, 51(17), 9469-9476. https://doi.org/10.1021/acs.est.7b01683

Nassar, N T, Graedel, T. E., \& Harper, E. M. (2015). By-product metals are technologically essential but have problematic supply. Science Advances, 1(3), e1400180-e1400180. https://doi.org/10.1126/sciadv.1400180

Nassar, Nedal T. (2017). Shifts and trends in the global anthropogenic stocks and flows of tantalum. Resources, Conservation and Recycling, 125(June), 233-250. https://doi.org/10.1016/j.resconrec.2017.06.002

Pauliuk, S. (2018). Critical appraisal of the circular economy standard BS 8001:2017 and a dashboard of quantitative system indicators for its implementation in organizations. Resources, Conservation and Recycling, 129, 81-92. https://doi.org/10.1016/j.resconrec.2017.10.019

Pauliuk, S., Kondo, Y., Nakamura, S., \& Nakajima, K. (2017). Regional distribution and losses of endof-life steel throughout multiple product life cycles-Insights from the global multiregional 
MaTrace model. Resources, Conservation and Recycling, 116, 84-93. https://doi.org/10.1016/j.resconrec.2016.09.029

Rechberger, H., \& Graedel, T. E. (2002). The contemporary European copper cycle: statistical entropy analysis. Ecological Economics, 42(1-2), 59-72. https://doi.org/10.1016/S0921-8009(02)001027

Reck, B. K., \& Rotter, V. S. (2012). Comparing Growth Rates of Nickel and Stainless Steel Use in the Early 2000s. Journal of Industrial Ecology, 16(4), 518-528. https://doi.org/10.1111/j.15309290.2012.00499.x

Reller, A. (2016). Criticality of metal based functional materials - How multi-functional transtechnical metal based materials are mobilized and how they get lost by dissipation. Current Opinion in Green and Sustainable Chemistry, 1, 25-27. https://doi.org/10.1016/j.cogsc.2016.08.001

Rudnick, R. L., \& Gao, S. (2003). Composition of the Continental Crust. In Treatise on Geochemistry (Vol. 3, pp. 1-64). https://doi.org/10.1016/B0-08-043751-6/03016-4

Wang, T., Müller, D. B., \& Graedel, T. E. (2007). Forging the anthropogenic iron cycle. Environmental Science and Technology, 41(14), 5120-5129. https://doi.org/10.1021/es062761t

Werner, T. T., Ciacci, L., Mudd, G. M., Reck, B. K., \& Northey, S. A. (2018). Looking Down Under for a Circular Economy of Indium. Environmental Science \& Technology, 52(4), 2055-2062. https://doi.org/10.1021/acs.est.7b05022

Winterstetter, A., Laner, D., Rechberger, H., \& Fellner, J. (2015). Framework for the evaluation of anthropogenic resources: A landfill mining case study - Resource or reserve? Resources, Conservation and Recycling, 96, 19-30. https://doi.org/10.1016/j.resconrec.2015.01.004

Zampori, L., \& Sala, S. (2017). Feasibility study to implement resource dissipation in LCA. https://doi.org/10.2760/869503

Zimmermann, T. (2015). Cycles of Critical Metals: Dissipative Losses and Potential Optimizations. Universität Bremen.

Zimmermann, T. (2017). Uncovering the Fate of Critical Metals: Tracking Dissipative Losses along the Product Life Cycle. Journal of Industrial Ecology, 21(5), 1198-1211. https://doi.org/10.1111/jiec.12492

Zimmermann, T., \& Gößling-Reisemann, S. (2013). Critical materials and dissipative losses: A screening study. Science of The Total Environment, 461-462, 774-780. https://doi.org/10.1016/j.scitotenv.2013.05.040 
Postprint

\title{
Quantitative assessment of dissipative losses of 18 metals
}

\section{Appendix A. Supplementary data}

\author{
Christoph Helbig ${ }^{*}$, a , Andrea Thorenz ${ }^{\mathrm{a}}$, Axel Tuma ${ }^{\mathrm{a}}$ \\ *Address correspondence to: christoph.helbig@wiwi.uni-augsburg.de \\ a: Resource Lab, Institute of Materials Resource Management, University of Augsburg, \\ Universitaetsstr. 16, 86159 Augsburg, Germany
}

Supplementary Material to:

Quantitative assessment of dissipative losses of 18 metals,

Resources, Conservation and Recycling Volume 153, February 2020, 104537/

https://www.sciencedirect.com/science/article/pii/S0921344919304434?via\%3Dihub

\begin{tabular}{|c|c|c|c|}
\hline Section Topic & Tables & Figures & Page \\
\hline 1. Notation of processes in global metal cycles & S1 & & S2 \\
\hline \multicolumn{4}{|l|}{ 2. Results of the global metal cycles } \\
\hline 2.1 Aluminum & & S1, S2 & S3 \\
\hline 2.2 Chromium & & S3, S4 & S4 \\
\hline 2.3 Iron & & S5, S6 & S5 \\
\hline 2.4 Cobalt & & S7, S8 & S6 \\
\hline 2.5 Nickel & & S9, S10 & S7 \\
\hline 2.6 Copper & & S11, S12 & S8 \\
\hline 2.7 Zinc & & S13, S14 & S9 \\
\hline 2.8 Gallium & & S15, S16 & S10 \\
\hline 2.9 Germanium & & S17, S18 & S11 \\
\hline 2.10 Selenium & & S19, S20 & S12 \\
\hline 2.11 Silver & & S21, S22 & S13 \\
\hline 2.12 Indium & & S23, S24 & S14 \\
\hline 2.13 Tin & & S25, S26 & S15 \\
\hline 2.14 Tellurium & & S27, S28 & S16 \\
\hline 2.15 Tantalum & & S29, S30 & S17 \\
\hline 2.16 Tungsten & & S31, S32 & S18 \\
\hline 2.17 Rhenium & & S33, S34 & S19 \\
\hline 2.18 Lead & & S35, S36 & S20 \\
\hline References & & & S21 \\
\hline
\end{tabular}




\section{Notation of processes in global metal cycles}

Table S1: Transformation processes of the analyzed metal cycles for a consistent material flow notation.

\begin{tabular}{|c|c|c|c|c|c|c|c|c|c|c|c|c|c|c|c|c|c|c|c|}
\hline Abbreviation & Process name & $\mathrm{Al}$ & $\mathrm{Cr}$ & $\mathrm{Fe}$ & Co & $\mathrm{Ni}$ & $\mathrm{Cu}$ & $\mathrm{Zn}$ & $\mathrm{Ga}$ & Ge & Se & $\mathrm{Ag}$ & In & Sn & Te & $\mathrm{Ta}$ & W & $\operatorname{Re}$ & $\mathrm{Pb}$ \\
\hline PEM.0 & Production & $\checkmark$ & $\checkmark$ & $\checkmark$ & $\checkmark$ & $\checkmark$ & $\checkmark$ & $\checkmark$ & $\checkmark$ & $\checkmark$ & $\checkmark$ & $\checkmark$ & $\checkmark$ & $\checkmark$ & $\checkmark$ & $\checkmark$ & $\checkmark$ & $\checkmark$ & $\sqrt{ }$ \\
\hline PEM.1 & Mining & $x$ & $x$ & $x$ & $\checkmark$ & $\checkmark$ & $\checkmark$ & $\checkmark$ & $\checkmark$ & $\checkmark$ & $\checkmark$ & $x$ & $\checkmark$ & $\checkmark$ & $\checkmark$ & $x$ & $\checkmark$ & $\checkmark$ & $x$ \\
\hline PEM.3 & Refining & $x$ & $x$ & $x$ & $\checkmark$ & $\checkmark$ & $\checkmark$ & $\checkmark$ & $\checkmark$ & $\checkmark$ & $\checkmark$ & $x$ & $\checkmark$ & $x$ & $\checkmark$ & $x$ & $x$ & $x$ & $x$ \\
\hline PEM.13 & Mining \& Refining & $\sqrt{ }^{a}$ & $x$ & $x$ & $x$ & $x$ & $x$ & $x$ & $x$ & $x$ & $x$ & $x$ & $x$ & $x$ & $x$ & $x$ & $x$ & $x$ & $x$ \\
\hline PEM.23 & Smelting \& Refining & $x$ & $x$ & $x$ & $x$ & $x$ & $x$ & $x$ & $x$ & $x$ & $x$ & $x$ & $x$ & $\checkmark$ & $x$ & $x$ & $x$ & $\checkmark$ & $x$ \\
\hline PEM.4 & Chemical treatment & $x$ & $x$ & $x$ & $x$ & $x$ & $x$ & $x$ & $x$ & $x$ & $x$ & $x$ & $x$ & $x$ & $x$ & $x$ & $\checkmark$ & $x$ & $x$ \\
\hline PEM.5 & Beneficiation & $x$ & $x$ & $\mathrm{X}$ & $x$ & 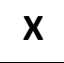 & $x$ & $\mathbf{x}$ & $\sqrt{ }$ & $\checkmark$ & $x$ & $x$ & $\sqrt{ }$ & $x$ & $\mathbf{x}$ & $x$ & $x$ & $x$ & $x$ \\
\hline F\&M.0 & $\begin{array}{ll}\text { Fabrication } & \& \\
\text { Manufacturing } & \end{array}$ & $\checkmark$ & $\sqrt{ }$ & $\checkmark$ & $\sqrt{ }$ & $\sqrt{ }$ & $\sqrt{ }$ & $\checkmark$ & $\checkmark$ & $\checkmark$ & $\checkmark$ & $\sqrt{ }$ & $\checkmark$ & $\sqrt{ }$ & $\checkmark$ & $\checkmark$ & $\checkmark$ & $\mathbf{X}$ & $\checkmark$ \\
\hline F\&M.1 & Fabrication & $\sqrt{ }$ & $x$ & $x$ & $x$ & $\sqrt{ }$ & $\sqrt{ }$ & $\sqrt{ }$ & $x$ & $x$ & $x$ & $x$ & $x$ & $x$ & $\mathrm{x}$ & $\mathbf{x}$ & $\sqrt{ }$ & $\sqrt{ }$ & $x$ \\
\hline F\&M.2 & Manufacturing & $\sqrt{ }$ & $x$ & $x$ & $x$ & $\sqrt{ }$ & $\sqrt{ }$ & $\checkmark$ & $x$ & $x$ & $x$ & $x$ & $x$ & $x$ & $x$ & $x$ & $\checkmark$ & $\checkmark$ & $x$ \\
\hline WMR.0 & Waste management & $\checkmark$ & $\checkmark$ & $\checkmark$ & $\checkmark$ & $\checkmark$ & $\checkmark$ & $\checkmark$ & $\checkmark$ & $\checkmark$ & $\checkmark$ & $\checkmark$ & $\checkmark$ & $\checkmark$ & $\checkmark$ & $\checkmark$ & $\checkmark$ & $\checkmark$ & $\sqrt{ }$ \\
\hline WMR.1 & Scrap market & $x$ & $x$ & $x$ & $\checkmark$ & $\checkmark$ & $\checkmark$ & $\checkmark$ & $\sqrt{ }$ & $\sqrt{ }$ & $\checkmark$ & $\checkmark$ & $\checkmark$ & $x$ & $\checkmark$ & $x$ & $\checkmark$ & $\checkmark$ & $x$ \\
\hline WMR.2 & Other materials & $\sqrt{ }$ & $\sqrt{ }$ & $x$ & $\sqrt{ }$ & $\sqrt{ }$ & $\checkmark$ & $\checkmark$ & $x$ & $x$ & $x$ & $x$ & $x$ & $\checkmark$ & $x$ & $\checkmark$ & $x$ & $x$ & $x$ \\
\hline ENV.0 & Environment & $\sqrt{ }$ & $\checkmark$ & $\sqrt{ }$ & $\checkmark$ & $\checkmark$ & $\checkmark$ & $\checkmark$ & $\checkmark$ & $\checkmark$ & $\mathrm{X}$ & $\checkmark$ & $\checkmark$ & $\checkmark$ & $x$ & $\checkmark$ & $\checkmark$ & $\checkmark$ & $\checkmark$ \\
\hline ENV.1 & Tailings \& Slags & $\sqrt{ }$ & $\checkmark$ & $\sqrt{ }$ & $\sqrt{ }$ & $\checkmark$ & $\checkmark$ & $\checkmark$ & $x$ & $x$ & $\checkmark$ & $\sqrt{ }$ & $x$ & $\checkmark$ & $\sqrt{ }$ & $\checkmark$ & $\checkmark$ & $\sqrt{ }$ & $\sqrt{ }$ \\
\hline ENV.2 & Landfills & $\checkmark$ & $\checkmark$ & $\sqrt{ }$ & $\checkmark$ & $\checkmark$ & $\checkmark$ & $\checkmark$ & $x$ & $x$ & $\checkmark$ & $\checkmark$ & $x$ & $\sqrt{ }$ & $\checkmark$ & $\checkmark$ & $\checkmark$ & $\sqrt{ }$ & $\checkmark$ \\
\hline ENV.3 & Lithosphere & $\sqrt{ }$ & $\checkmark$ & $\sqrt{ }$ & $\sqrt{ }$ & $\sqrt{ }$ & $\sqrt{ }$ & $\sqrt{ }$ & $\sqrt{ }$ & $\sqrt{ }$ & $\sqrt{ }$ & $\checkmark$ & $\checkmark$ & $\sqrt{ }$ & $\sqrt{ }$ & $\sqrt{ }$ & $\checkmark$ & $\sqrt{ }$ & $\checkmark$ \\
\hline
\end{tabular}

$\checkmark=$ Process used in this model, $\mathbf{X}=$ Process not used in this model

a For aluminum, the Smelting process comes after the process Mining \& Refining 


\section{Results of the global metal cycles}

\subsection{Aluminum}

Aluminum material flows displayed in Figure S1 are identical to the mean of the "2014 global aluminum cycle with uncertainty calculation" from Bertram and colleagues (Bertram et al. 2017, fig. 2b).

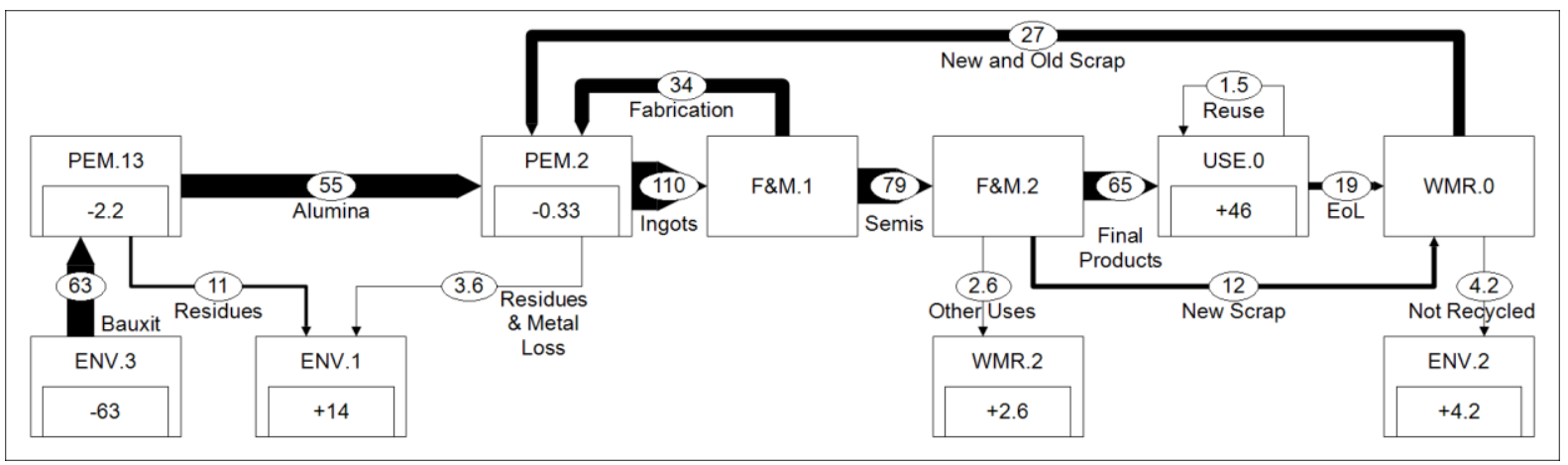

Figure S1: Global metal cycle for aluminum for the year 2014 in megatons (1 Mt = $1 \mathrm{Tg}$ ) (Bertram et al. 2017, fig. 2b).

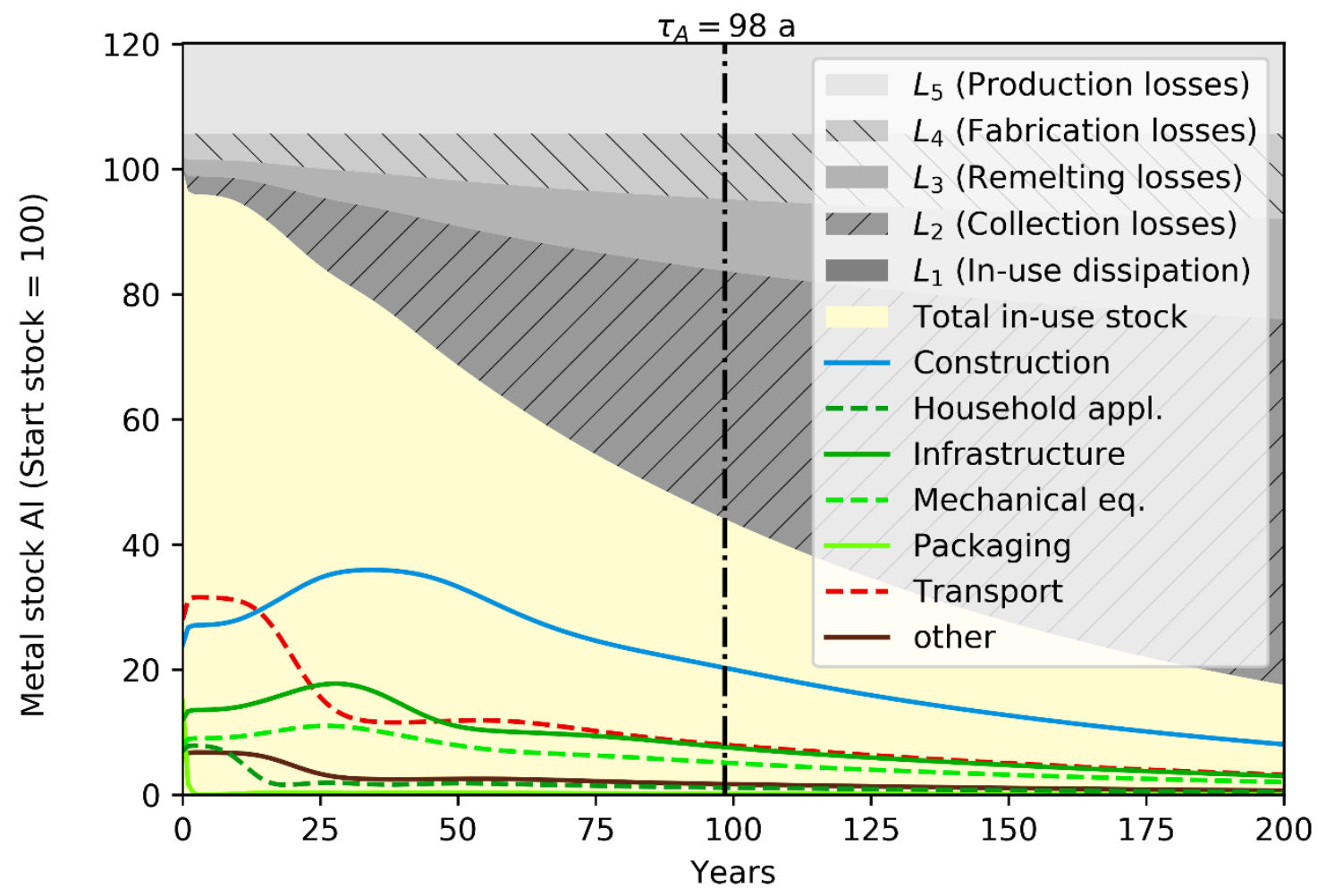

Figure S2: Metal stocks of a primary production cohort of aluminum in the anthroposphere by demand sectors and dissipative losses. In-use dissipation is negligibly small. 


\subsection{Chromium}

Chromium material flows displayed in Figure S3 are identical to the "global-level best-estimate chromium cycle, ca. 2000" by Johnson and colleagues (Johnson et al. 2006, fig. 3).

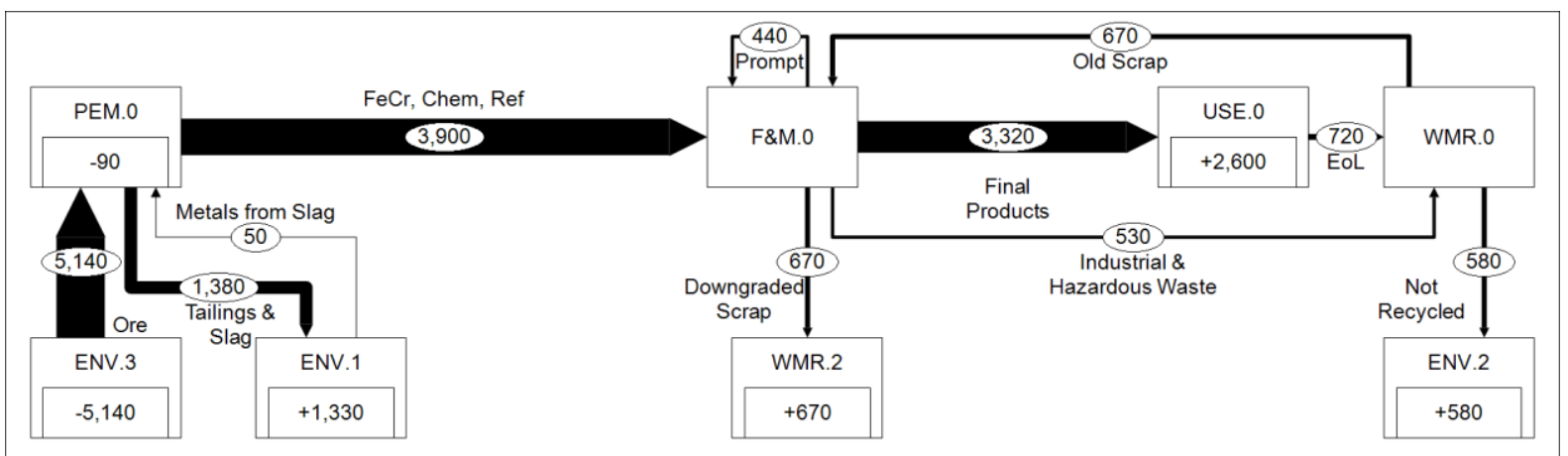

Figure S3: Global metal cycle for chromium around the year 2000 in kilotons (1 kt = $1 \mathrm{Gg}$ ) (Johnson et al. 2006,

fig. 3).

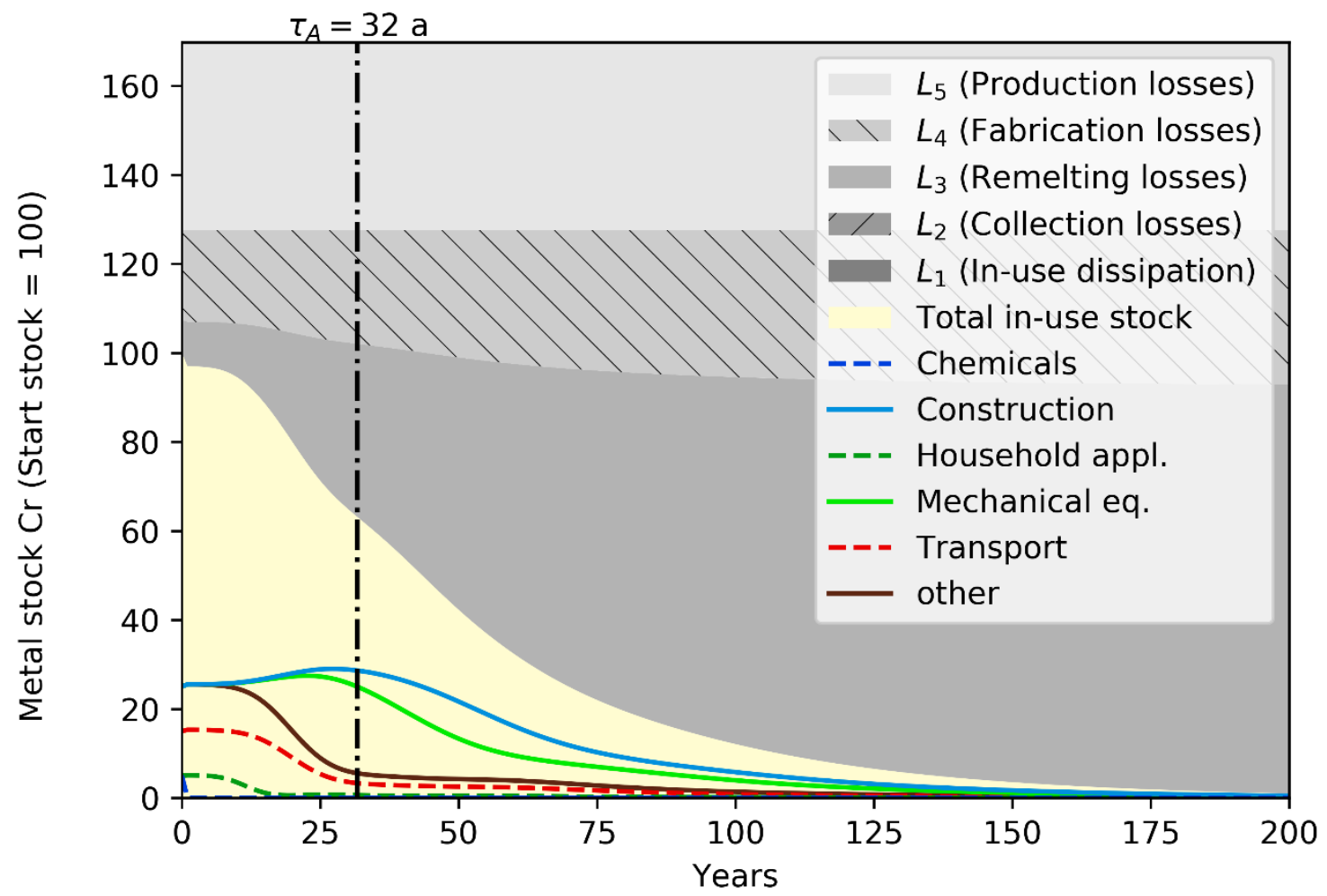

Figure S4: Metal stocks of a primary production cohort of chromium in the anthroposphere by demand sectors and dissipative losses. In-use dissipation and Collection losses are negligibly small. 
Postprint Helbig et al. (2020): Resources, Conservation and Recycling 153, 104537 https://doi.org/10.1016/j.resconrec.2019.104537

\subsection{Iron}

Iron material flows displayed in Figure S5 are identical to the "global-level iron cycle, best estimate for ca. 2000" by Wang and colleagues (Wang et al. 2007, fig. 7).

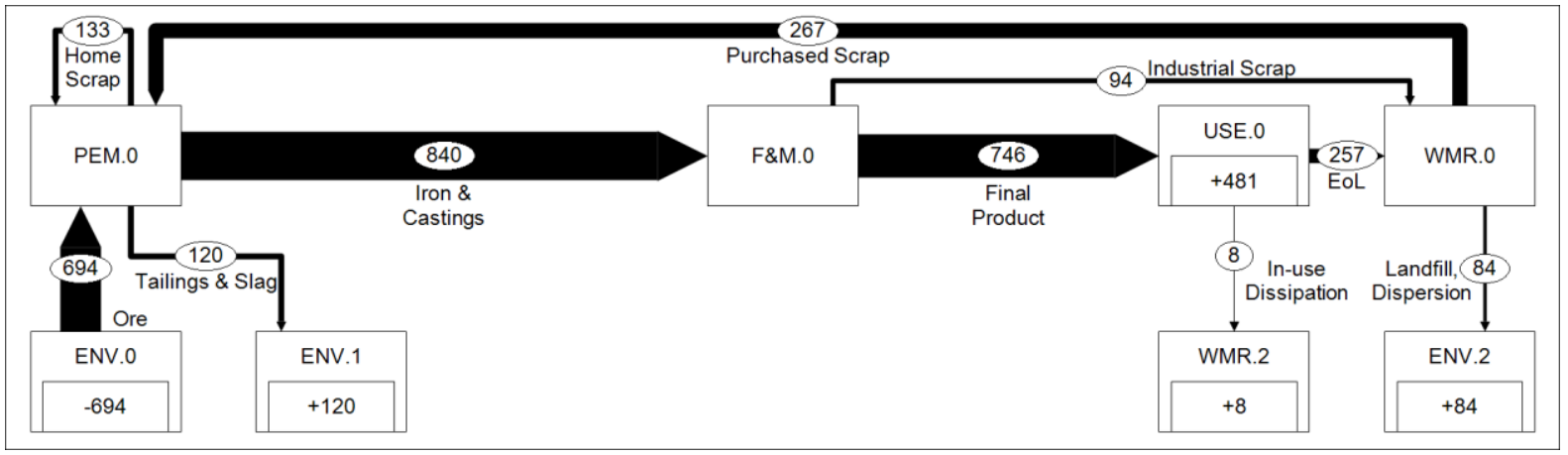

Figure S5: Global metal cycle for iron around the year 2000 in Megatons (1 Mt = $1 \mathrm{Tg}$ ) (Wang et al. 2007, fig. 7).

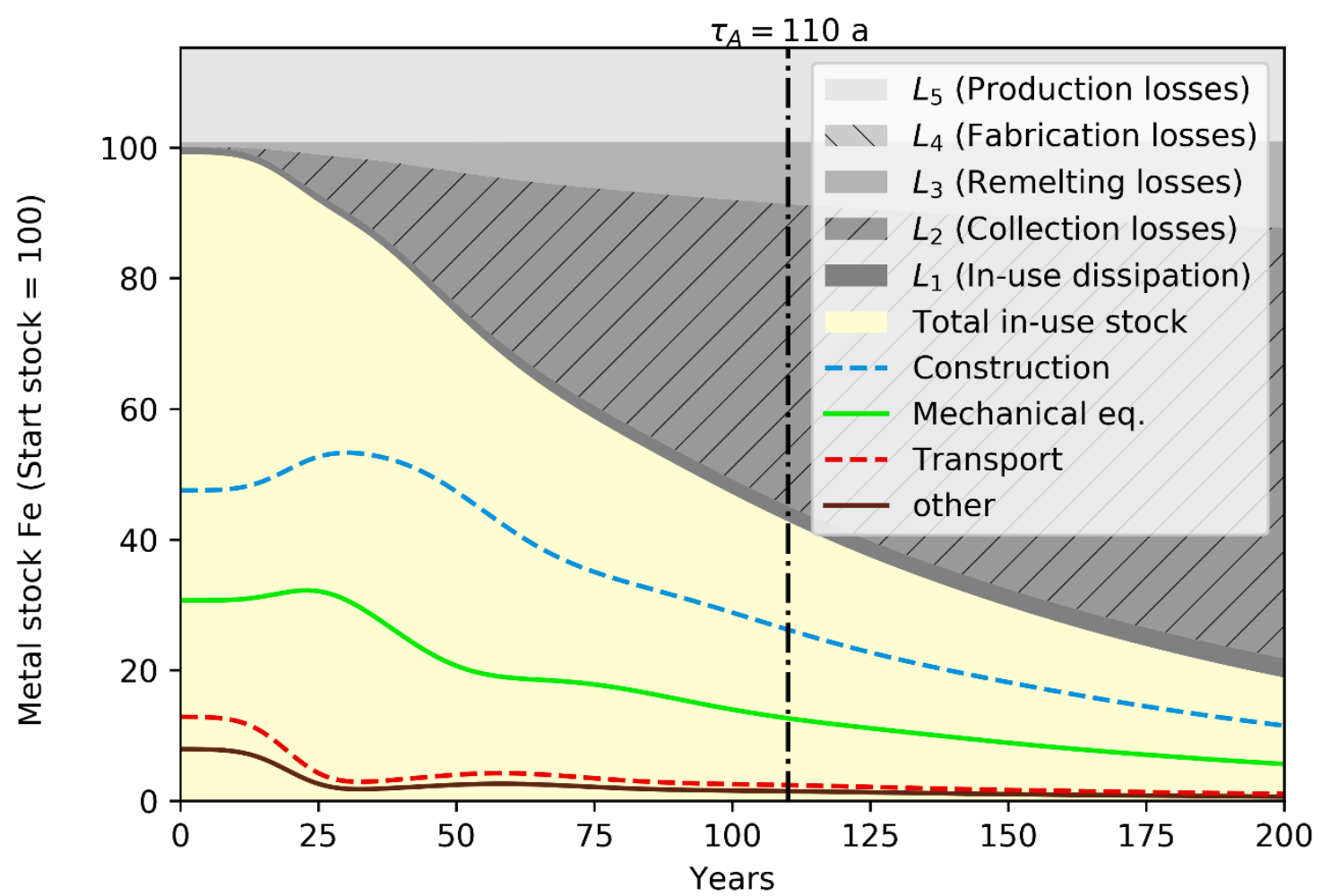

Figure S6: Metal stocks of a primary production cohort of iron in the anthroposphere by demand sectors and dissipative losses. Fabrication losses and In-use dissipation are negligibly small. 


\subsection{Cobalt}

Cobalt material flows displayed in Figure S6 are identical to the "2005 best estimate for the planet" by Harper and colleagues (Harper et al. 2012, fig. 6).

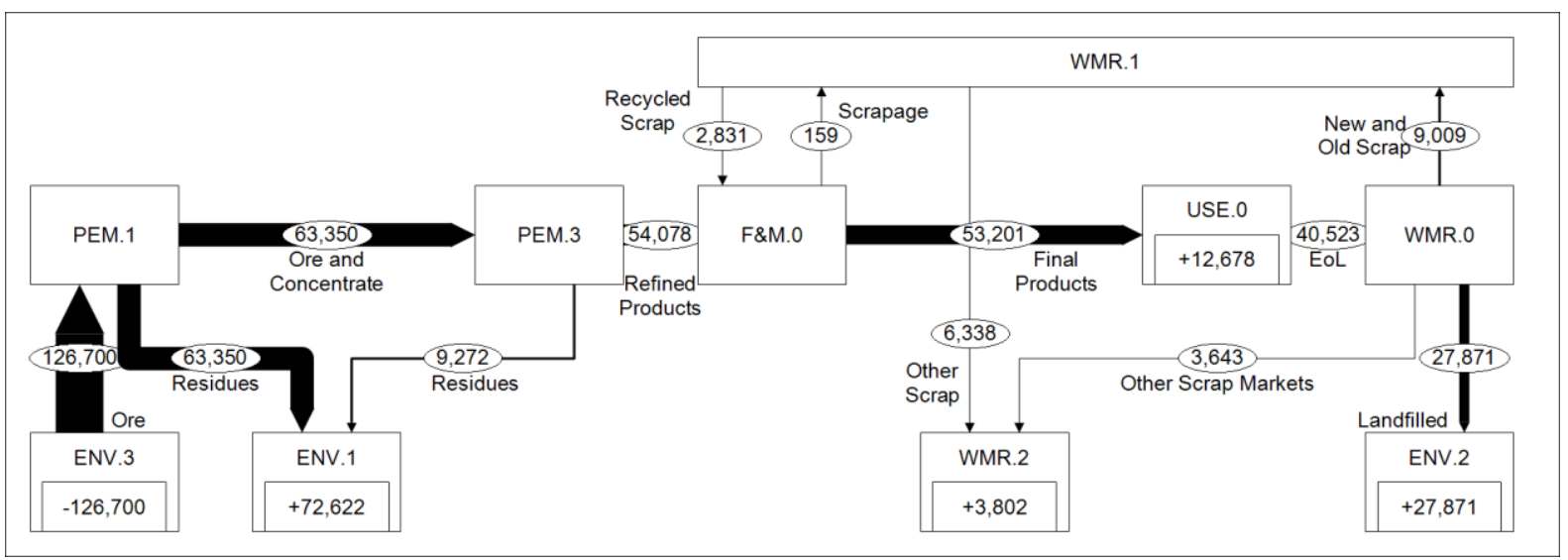

Figure S7: Global metal cycle for cobalt for the year 2005 in metric tons $(1 \mathrm{t}=1 \mathrm{Mg}$ ) (Harper et al. 2012, fig. 6).

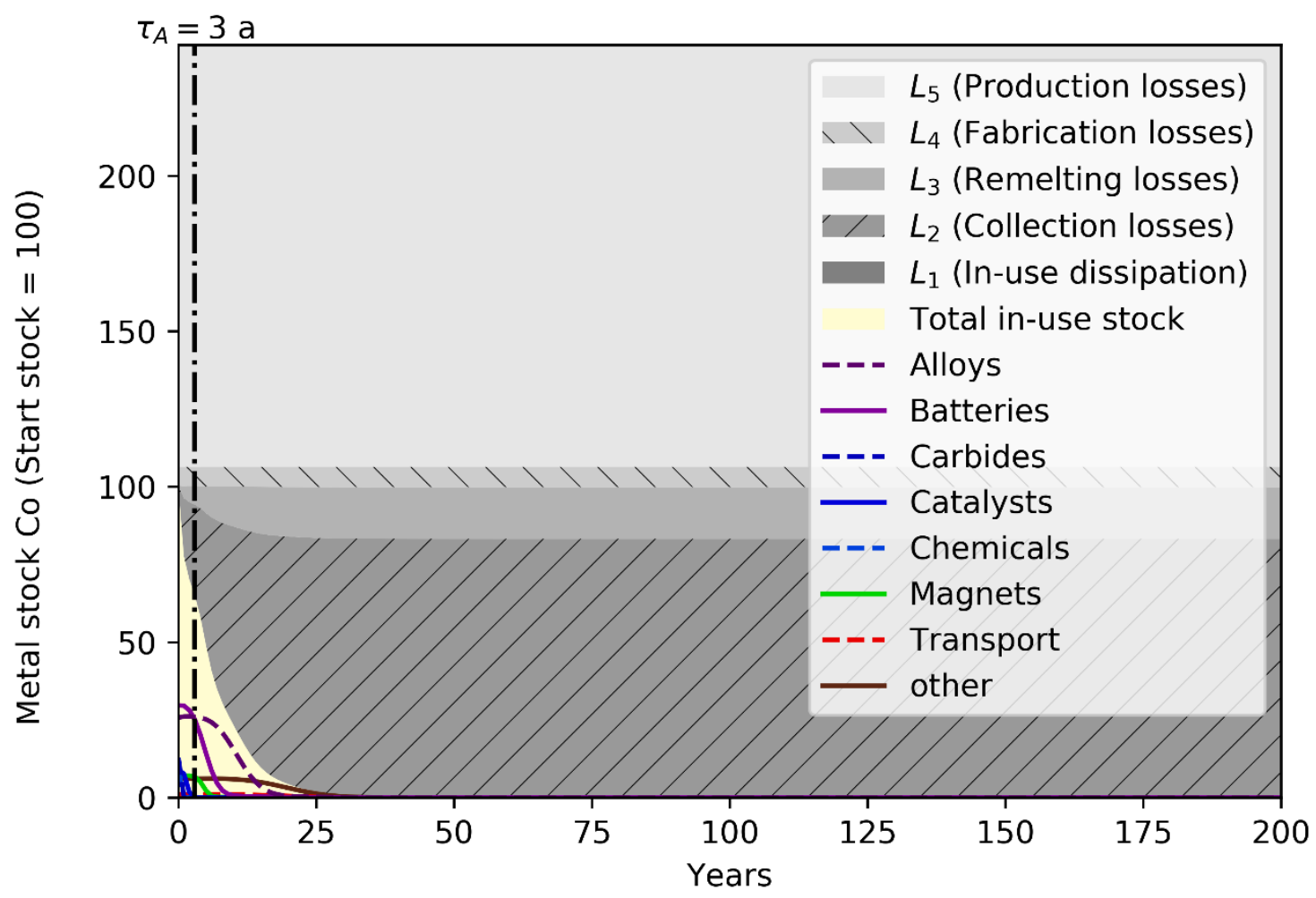

Figure S8: Metal stocks of a primary production cohort of cobalt in the anthroposphere by demand sectors and dissipative losses. In-use dissipation is negligibly small. 


\subsection{Nickel}

Nickel material flows displayed in Figure S9 are calculated from the "world nickel cycle [...] in 2005" of Reck and Rotter (Reck and Rotter 2012, fig. S2b). In the case of imbalances between inflowassessed and outflow-assessed material flows, here only the mean of outflowing and inflowing material flows is displayed.

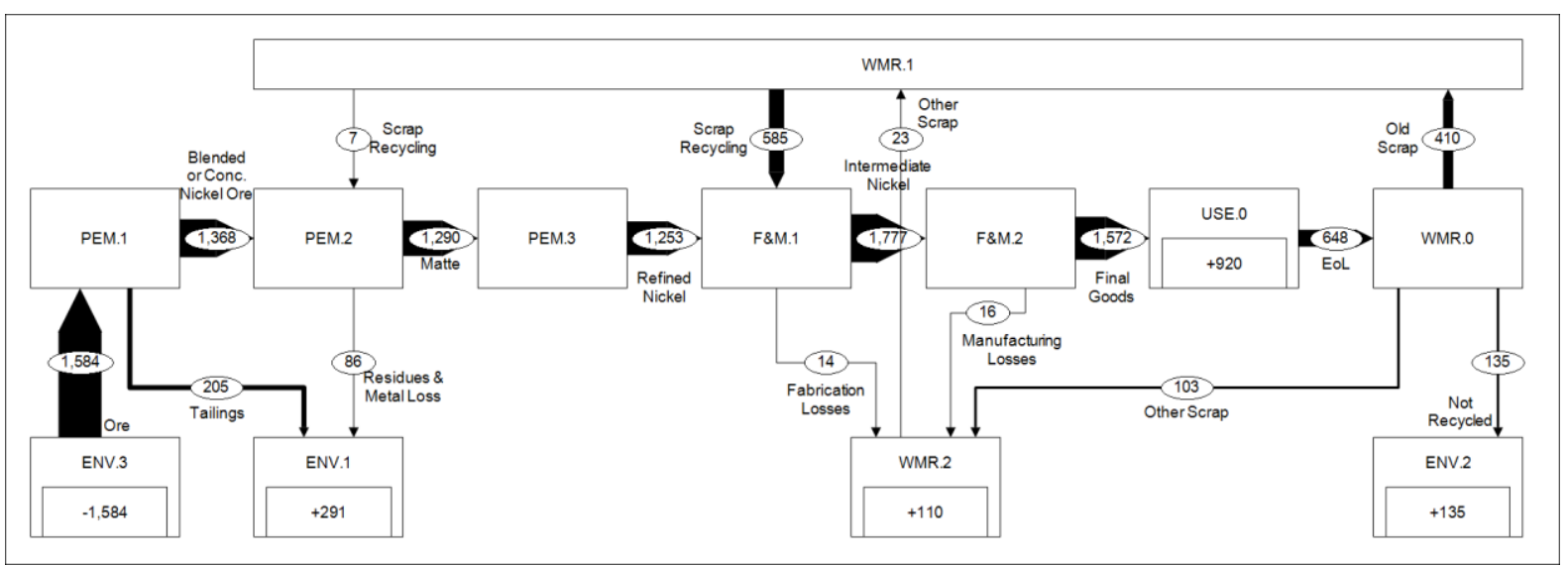

Figure S9: Global metal cycle for nickel around the year 2005 in kilotons (1 kt = $1 \mathrm{Gg}$ ) (Reck and Rotter 2012, fig. S2b).

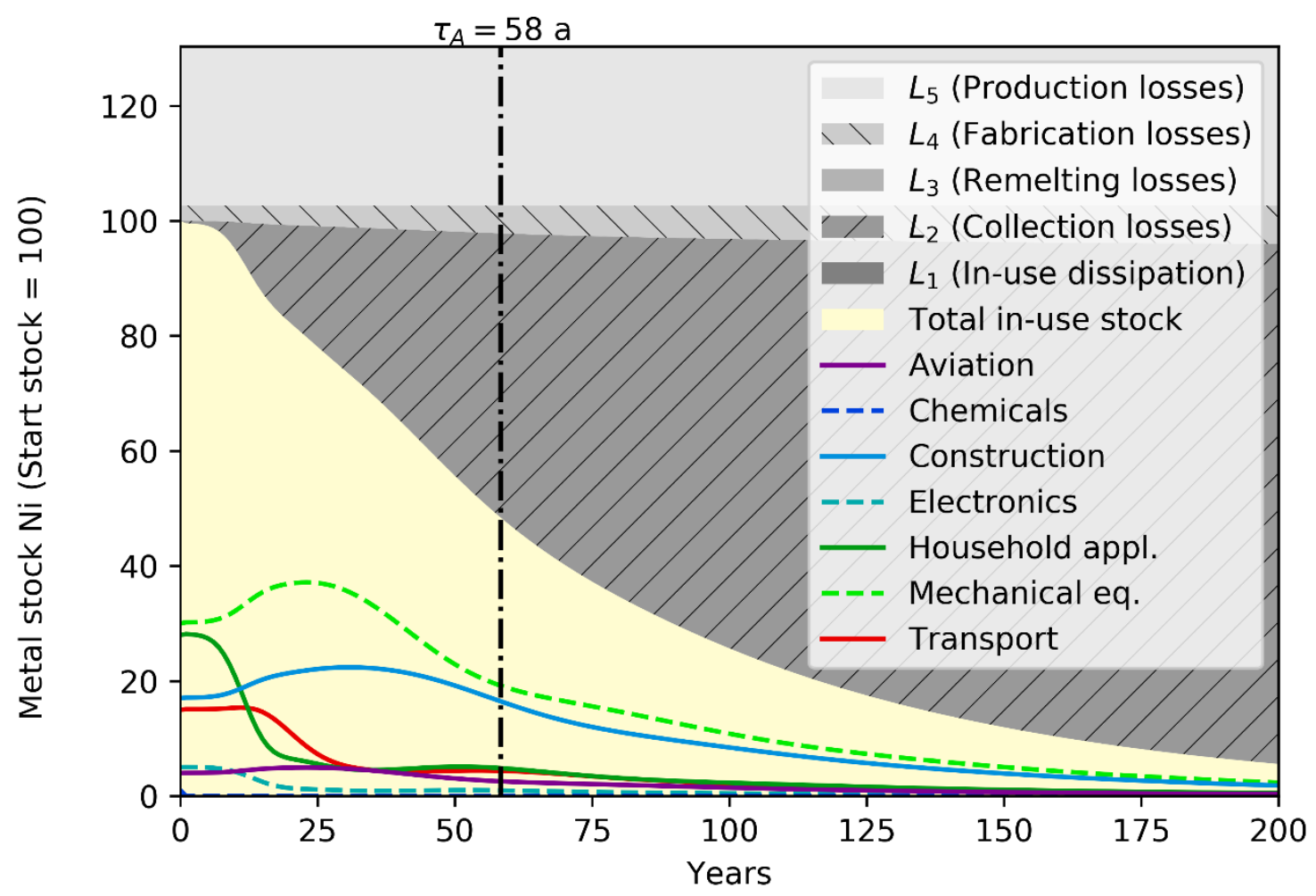

Figure S10: Metal stocks of a primary production cohort of nickel in the anthroposphere by demand sectors and dissipative losses. Remelting losses and In-use dissipation are negligibly small. 


\subsection{Copper}

Copper material flows displayed in Figure S11 are calculated from the Sankey diagram display of global copper flows in 2011 of Glöser-Chahoud (Glöser-Chahoud 2017, fig. 5.8). Material flows are identical to the original figure except for the additional consideration of copper losses during mining to tailings which are quantified to be " $18 \%$ of the copper content in the exploited ore" by (Glöser et al. 2013).

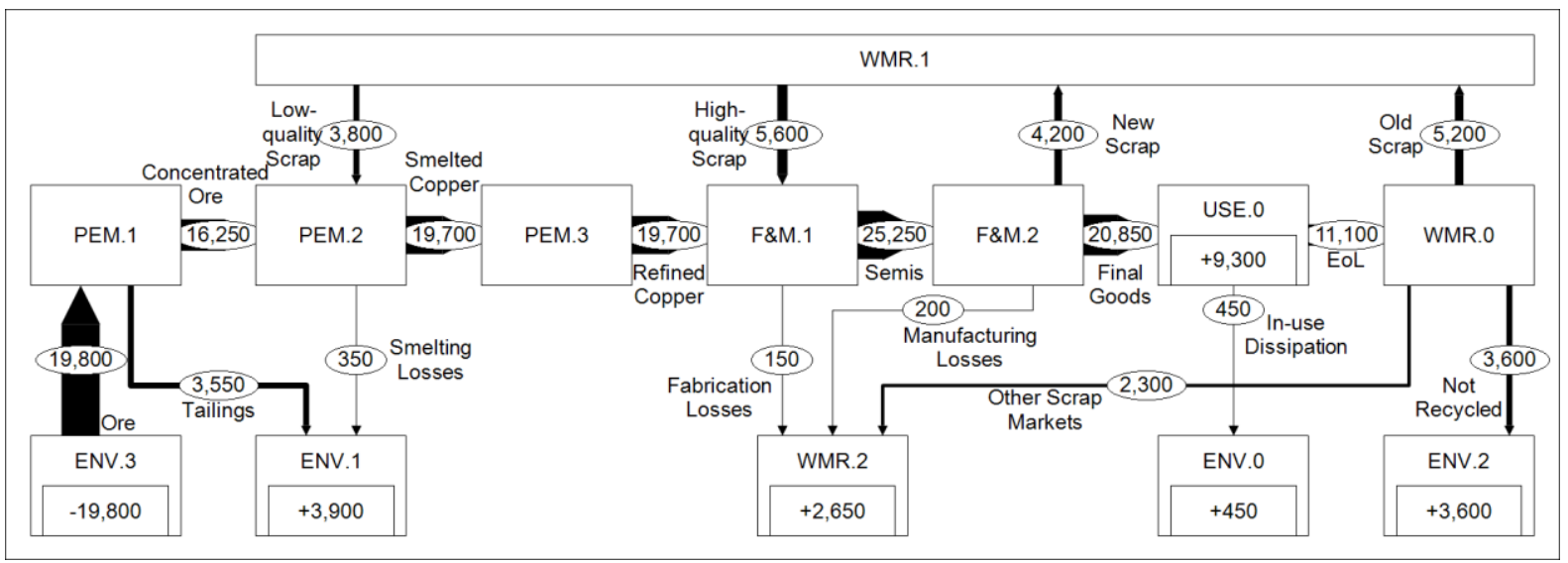

Figure S11: Global metal cycle for copper for the year 2011 in kilotons (1 kt = $1 \mathrm{Gg}$ ) (Glöser-Chahoud 2017, fig. 5.8).

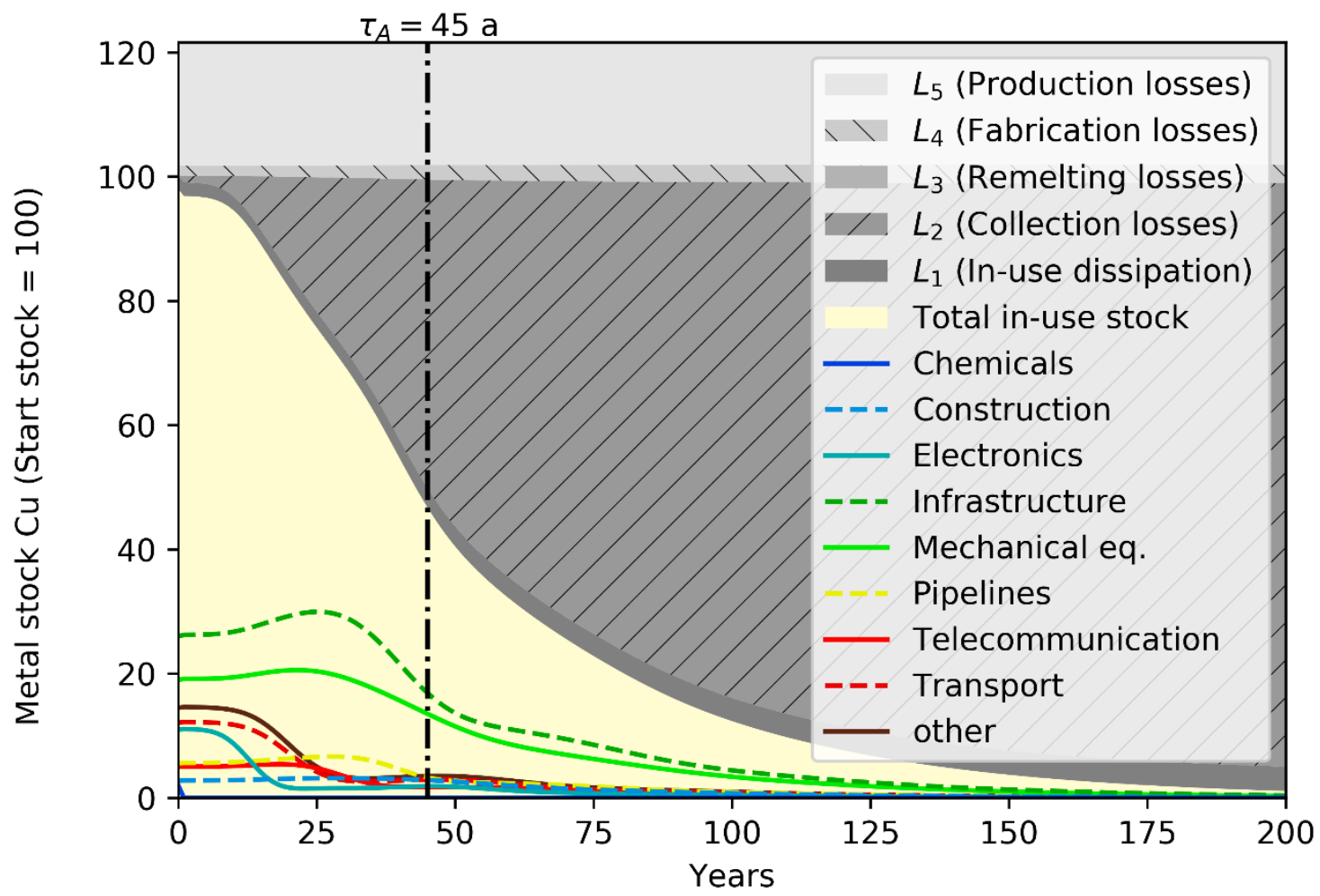

Figure S12: Metal stocks of a primary production cohort of copper in the anthroposphere by demand sectors and dissipative losses. Remelting losses are negligibly small. 


\subsection{Zinc}

Zinc material flows displayed in Figure S13 are calculated from the "base case 2010 global anthropogenic cycle of zinc" of Meylan and Reck (Meylan and Reck 2017, fig. 5a). In the case of imbalances between inflow-assessed and outflow-assessed material flows, here only the mean of outflowing and inflowing material flows is displayed.

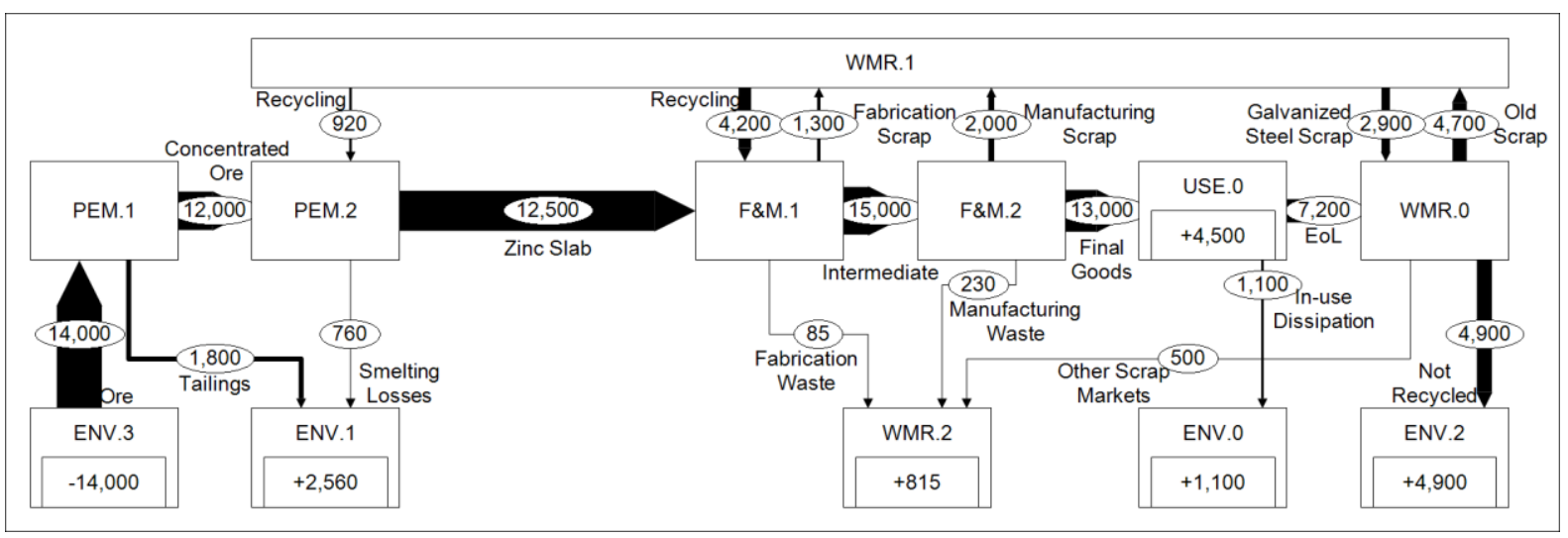

Figure S13: Global metal cycle for zinc for the year 2010 in kilotons (1 kt = $1 \mathrm{Gg}$ ) (Meylan and Reck 2017, fig.

5a).

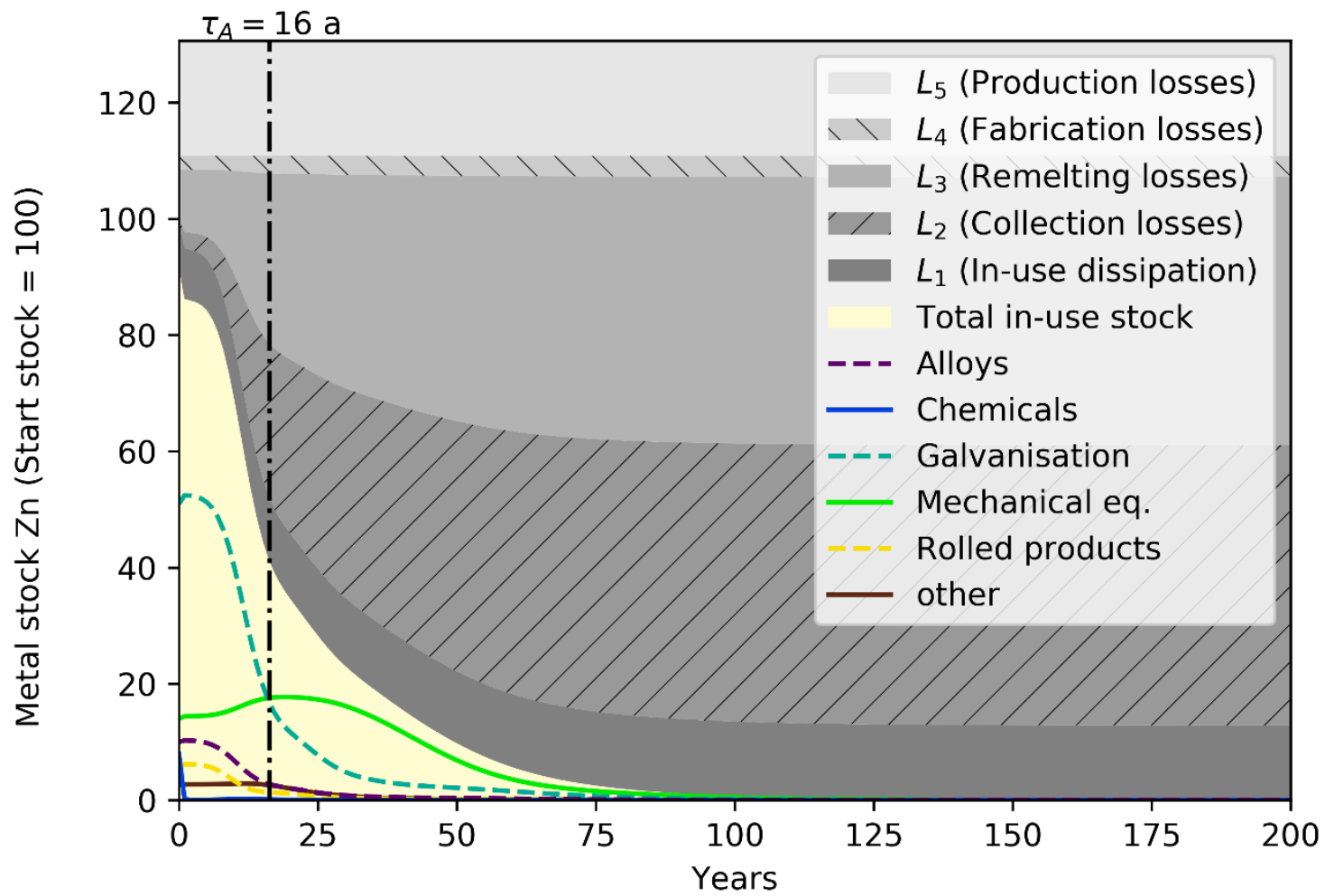

Figure S14: Metal stocks of a primary production cohort of zinc in the anthroposphere by demand sectors and dissipative losses. 


\subsection{Gallium}

Gallium material flows displayed in Figure S15 are identical to the "global substance flow analysis of gallium in 2011" by Licht and colleagues (Licht et al. 2015, fig. 2). Parallel processes in production, manufacturing and the use phase are jointly displayed.

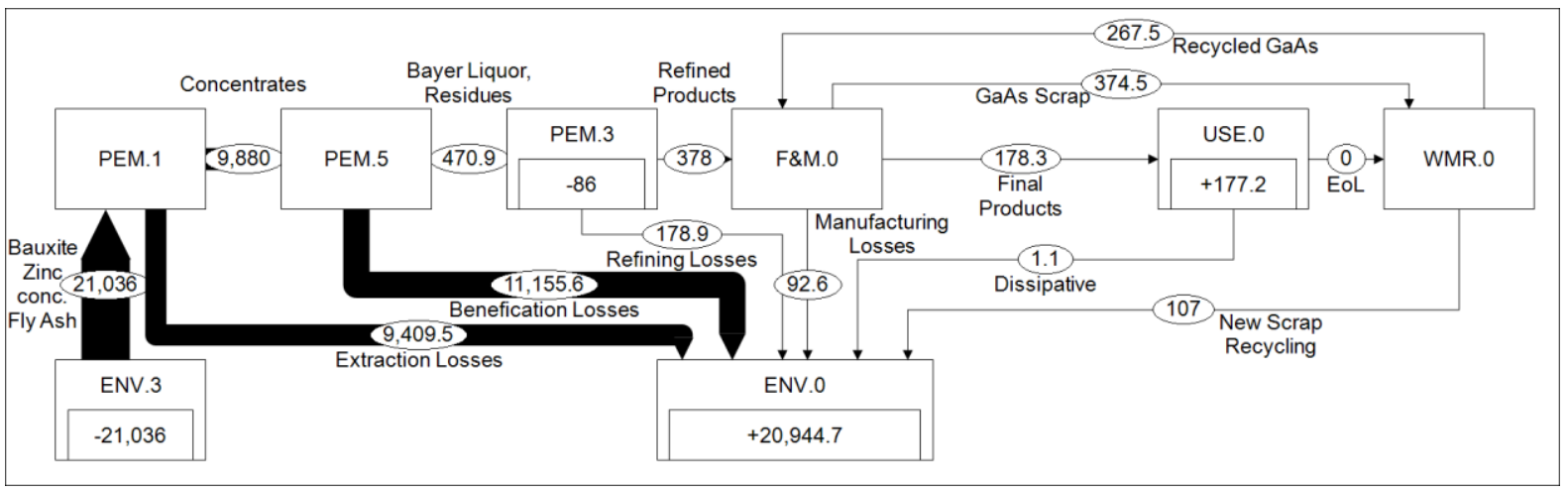

Figure S15: Global metal cycle for gallium for the year 2011 in metric tons (1 t = $1 \mathrm{Mg}$ ) (Licht et al. 2015, fig. 2).

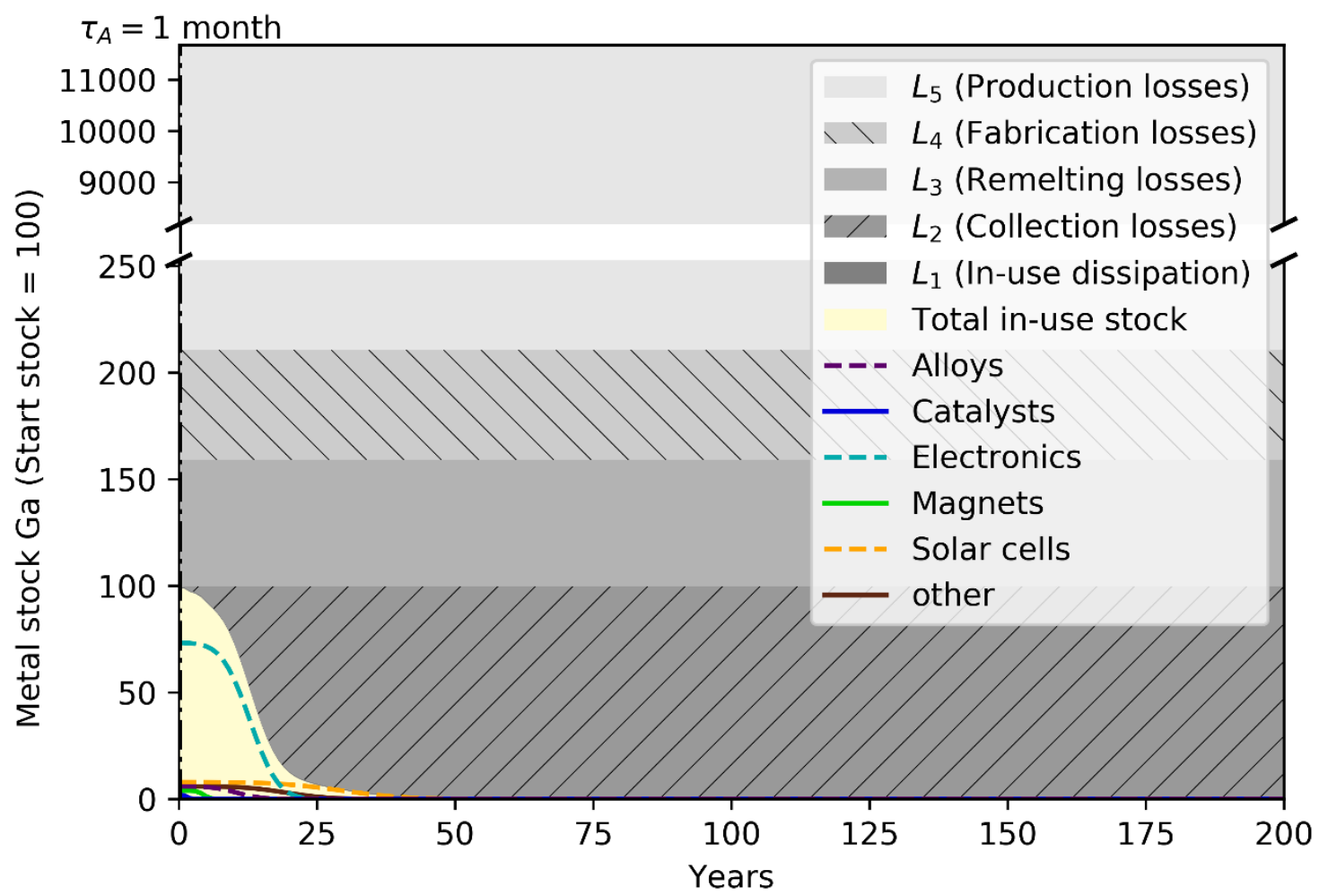

Figure S16: Metal stocks of a primary production cohort of gallium in the anthroposphere by demand sectors and dissipative losses. In-use dissipation is negligibly small. Ordinate is broken in the area of Production losses. 


\subsection{Germanium}

Germanium material flows displayed in Figure S17 are identical to the "global substance flow analysis of germanium in 2011" by Licht and colleagues (Licht et al. 2015, fig. 3). Parallel processes in production, manufacturing and the use phase are jointly displayed.

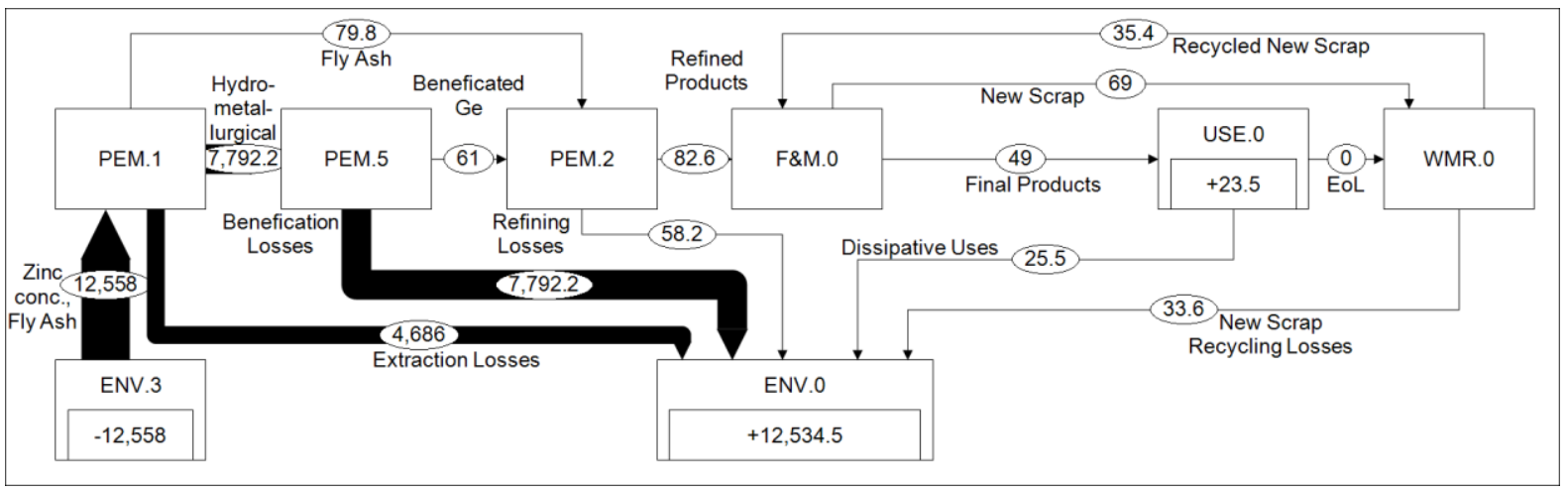

Figure S17: Global metal cycle for Germanium for the year 2011 in metric tons (1 $t=1 \mathrm{Mg}$ ) (Licht et al. 2015, fig. 3).

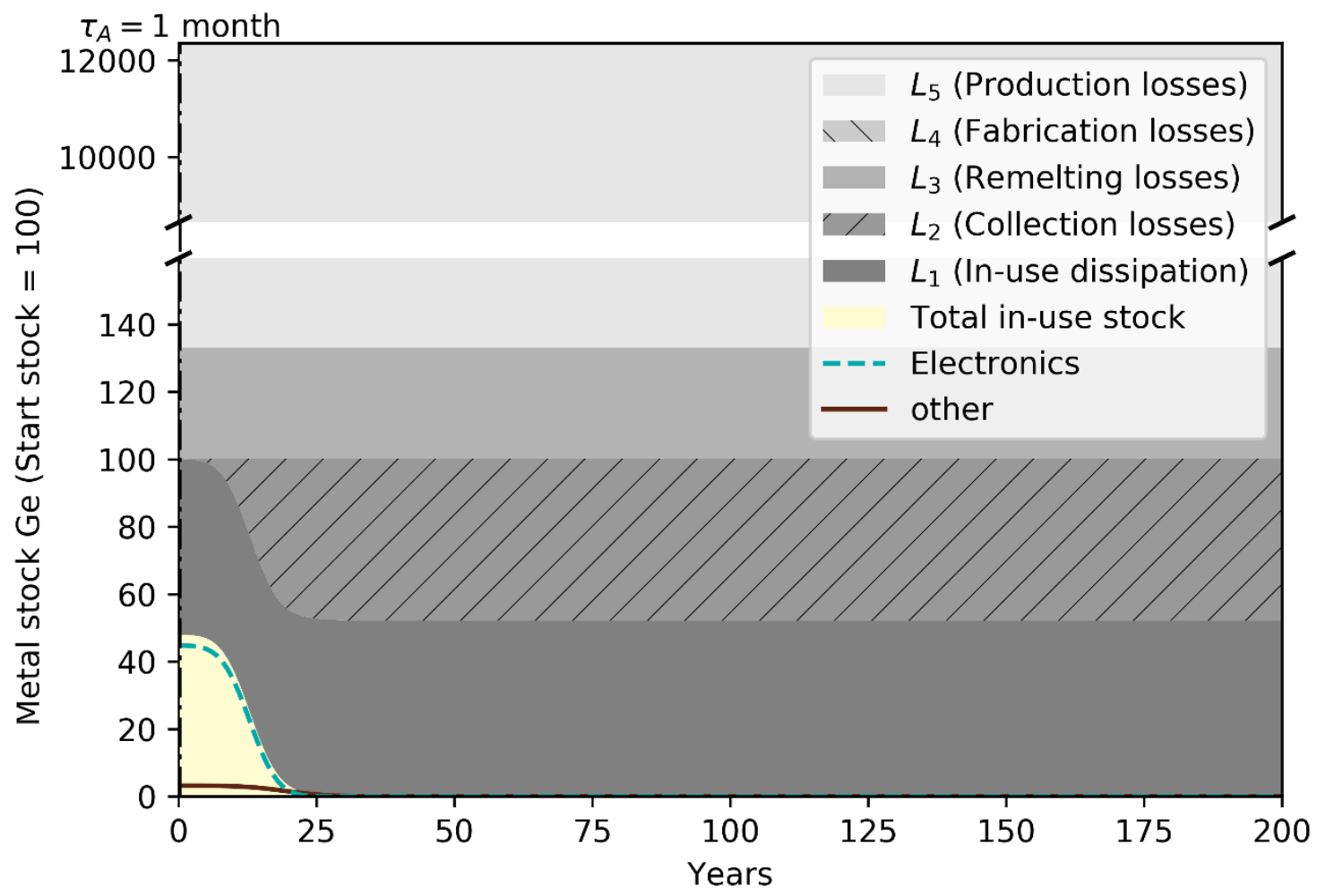

Figure S18: Metal stocks of a primary production cohort of germanium in the anthroposphere by demand sectors and dissipative losses. Fabrication losses are negligibly small. Ordinate is broken in the area of Production losses. 
Postprint Helbig et al. (2020): Resources, Conservation and Recycling 153, 104537

https://doi.org/10.1016/j.resconrec.2019.104537

\section{$2.10 \quad$ Selenium}

Selenium material flows displayed in Figure S19 are identical to the "global selenium [cycle] for the [year] [...] 2010" by Kavlak and Graedel (Kavlak and Graedel 2013a, fig. 3d).

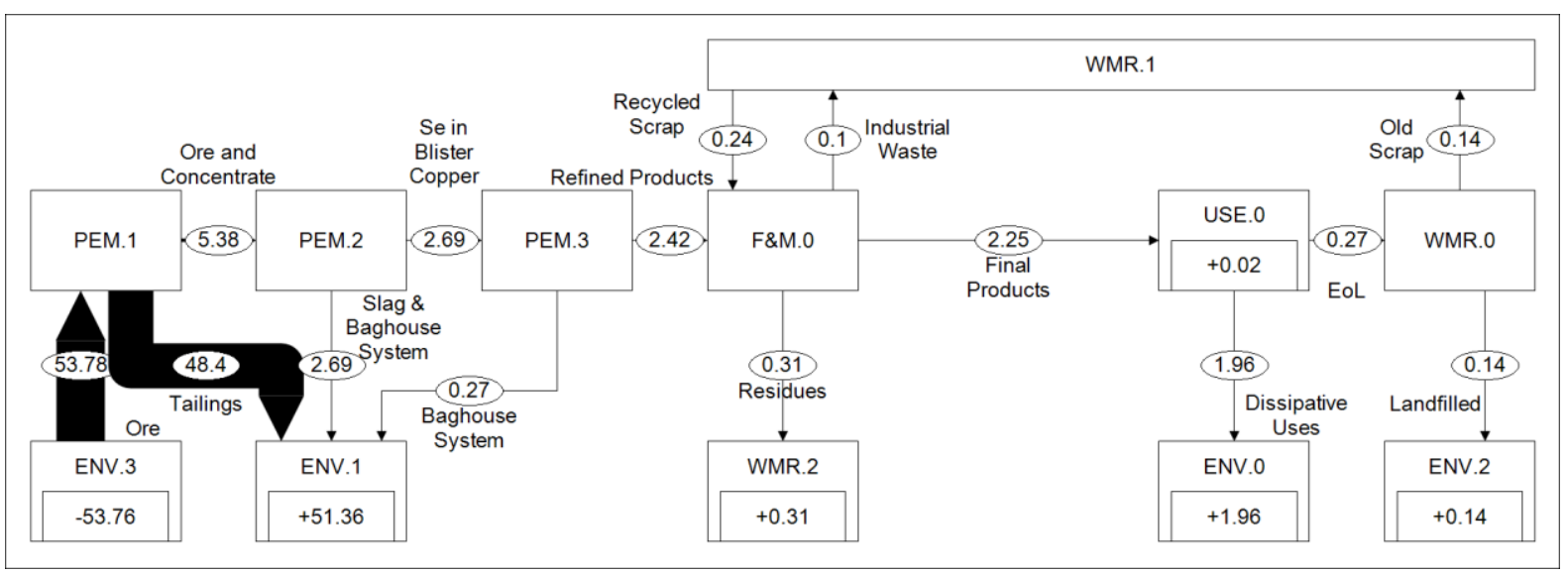

Figure S19: Global metal cycle for selenium for the year 2010 in kilotons (1 kt = $1 \mathrm{Gg}$ ) (Kavlak and Graedel 2013a, fig. 3d).

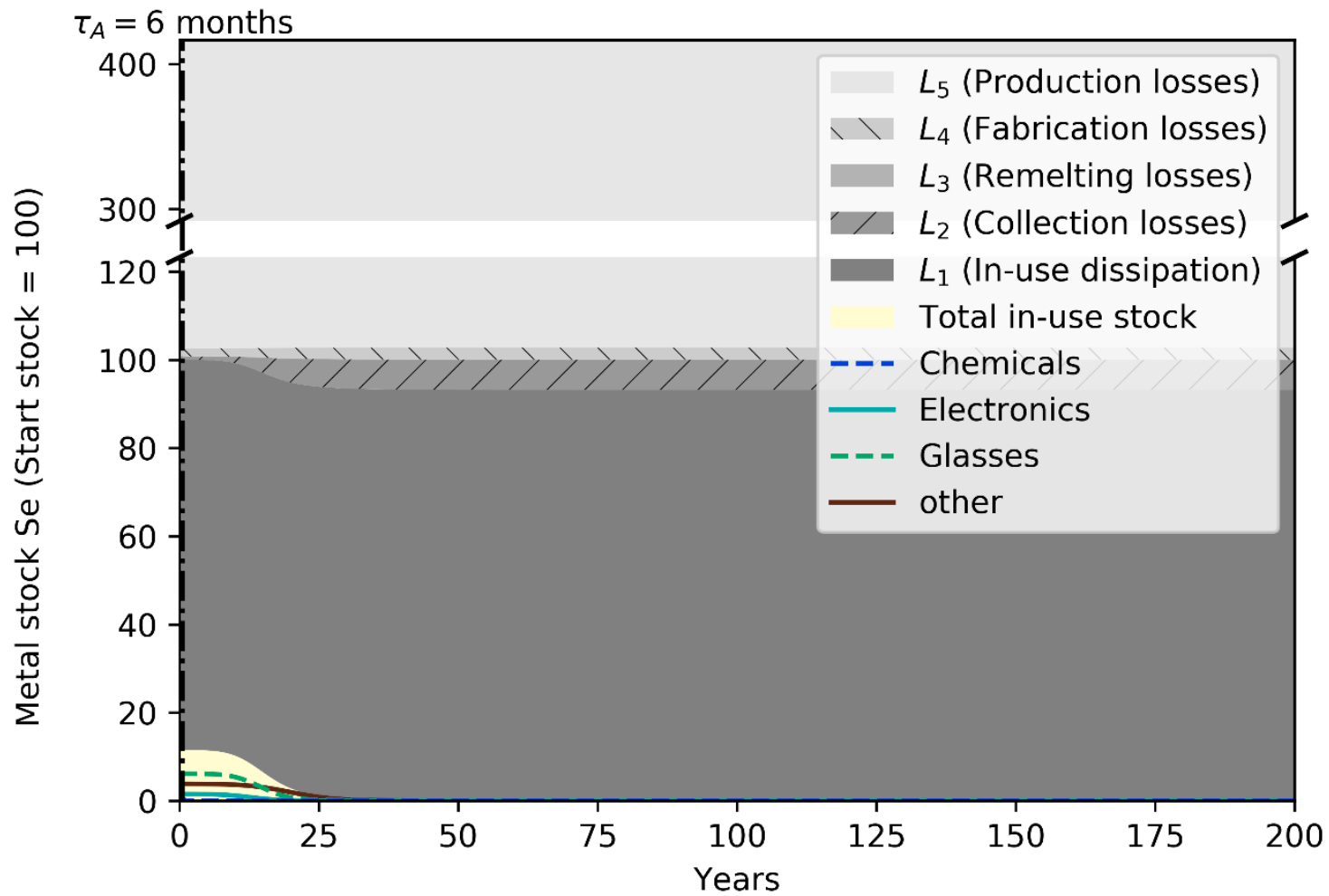

Figure S20: Metal stocks of a primary production cohort of selenium in the anthroposphere by demand sectors and dissipative losses. Remelting losses are negligibly small. Ordinate is broken in the area of Production losses. 
Postprint Helbig et al. (2020): Resources, Conservation and Recycling 153, 104537

https://doi.org/10.1016/j.resconrec.2019.104537

\section{$2.11 \quad$ Silver}

Silver material flows displayed in Figure S21 are identical to the "global-level best-estimate silver cycle, ca. 1997" by Johnson and colleagues (Johnson et al. 2005, fig. 4).

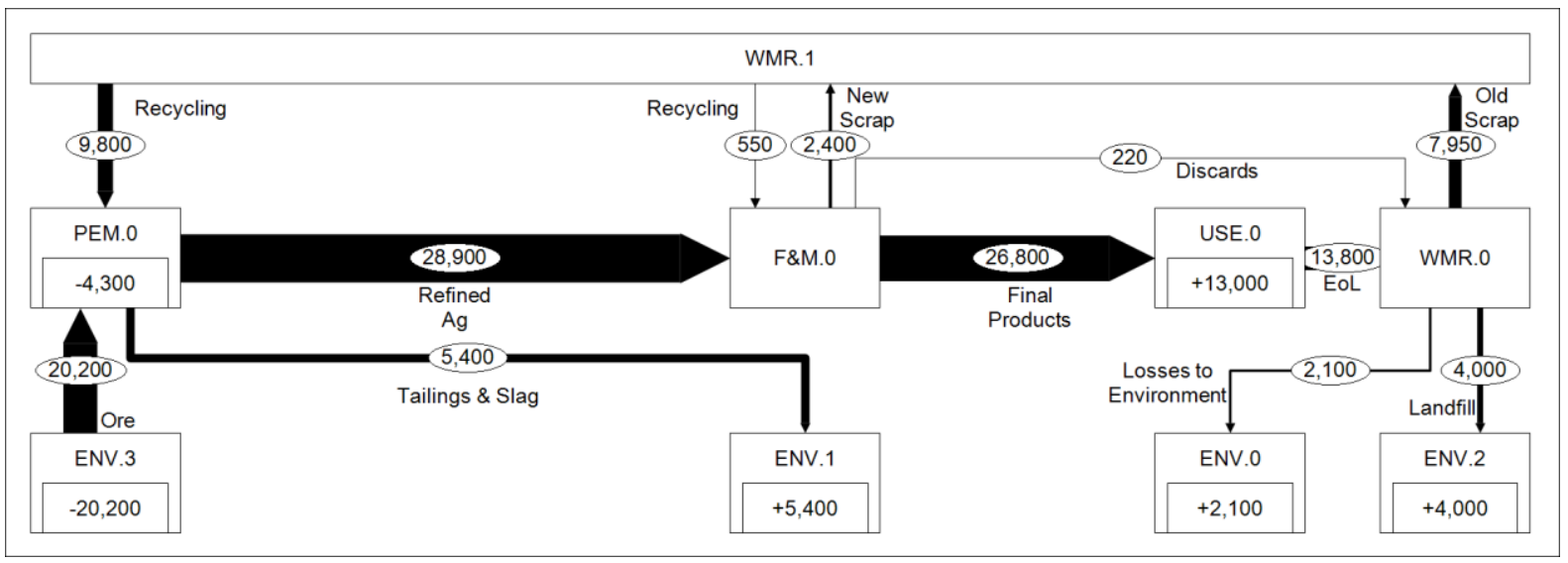

Figure S21: Global metal cycle for silver for the year 1997 in metric tons (1 t = $1 \mathrm{Mg}$ ) (Johnson et al. 2005, fig. 4).

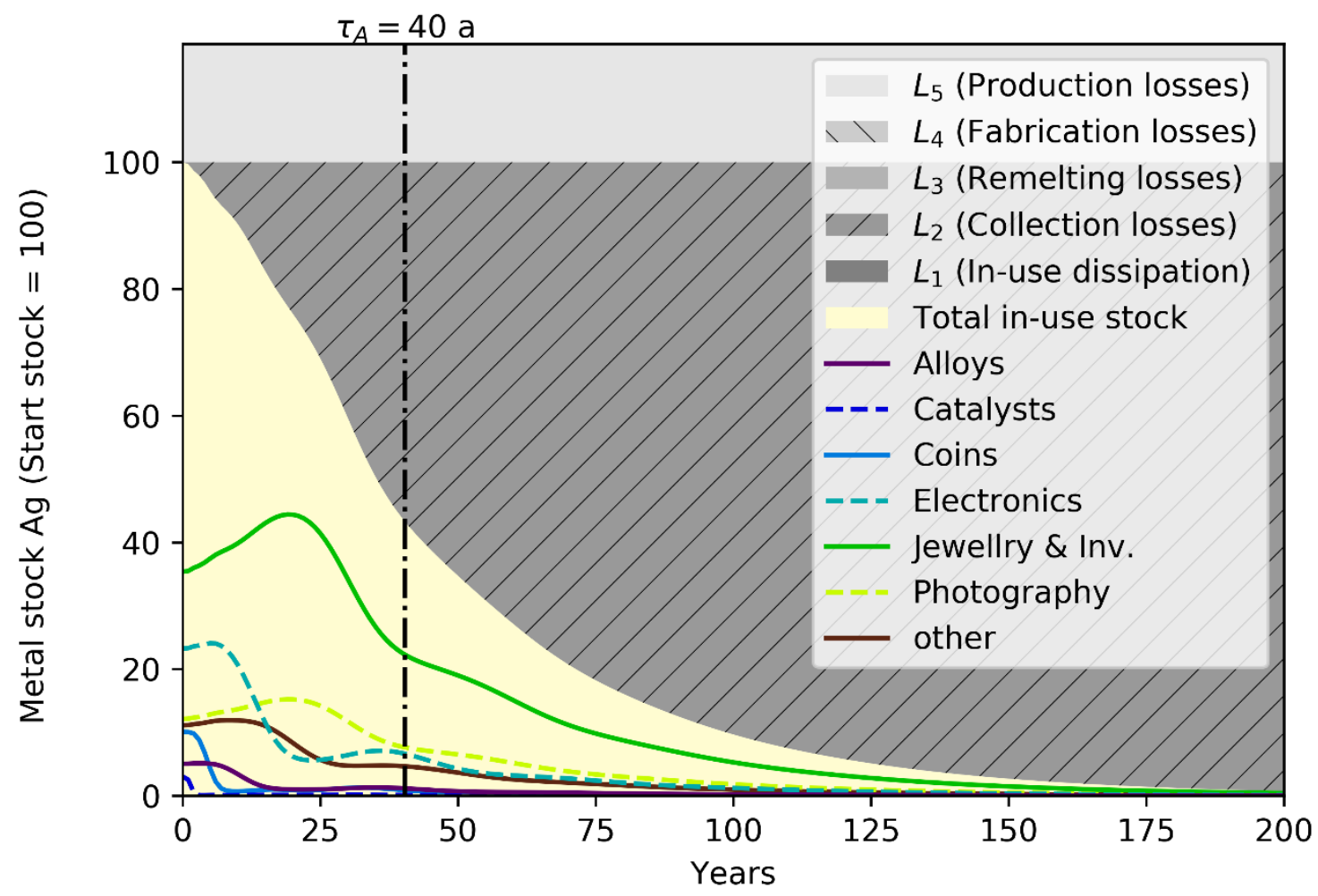

Figure S22: Metal stocks of a primary production cohort of silver in the anthroposphere by demand sectors and dissipative losses. Fabrication losses, Remelting losses and In-use dissipation are negligibly small. 
Postprint Helbig et al. (2020): Resources, Conservation and Recycling 153, 104537

https://doi.org/10.1016/j.resconrec.2019.104537

\subsection{Indium}

Indium material flows displayed in Figure S23 are identical to the "global substance flow analysis of indium in 2011" by Licht and colleagues (Licht et al. 2015, fig. 4). Parallel processes in production, manufacturing and the use phase are jointly displayed.

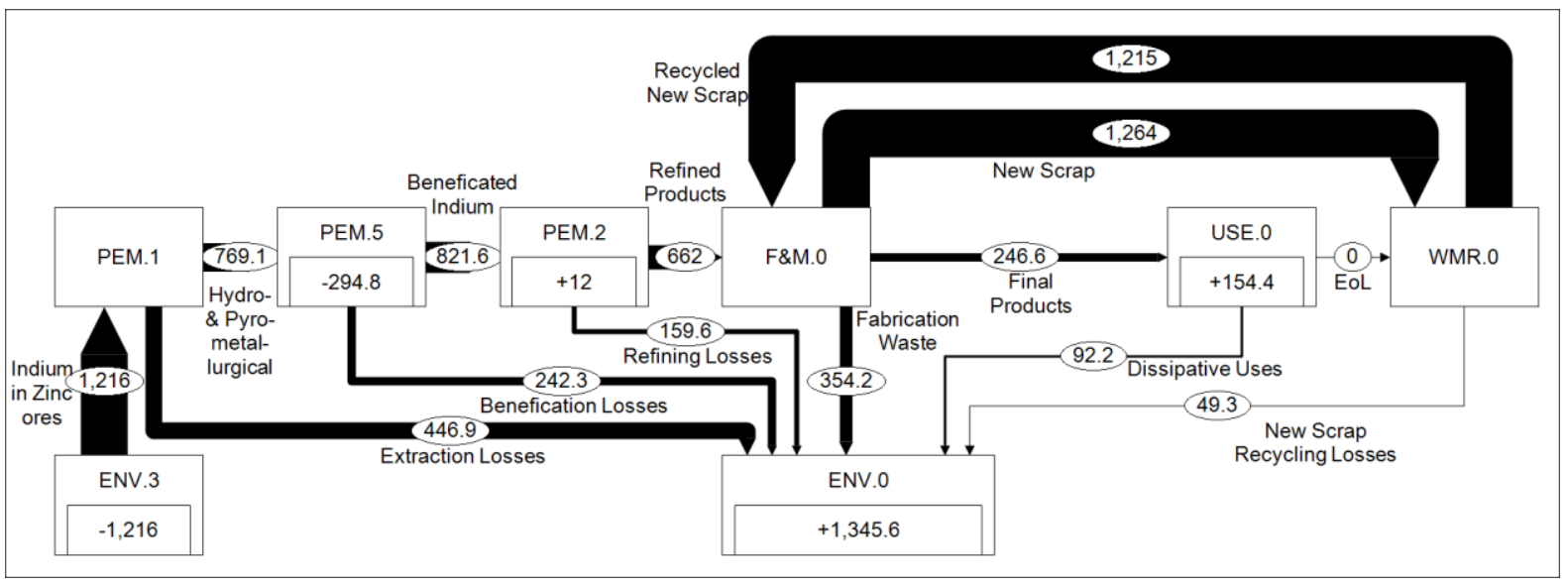

Figure S23: Global metal cycle for indium for the year 2011 in metric tons (1 t = $1 \mathrm{Mg})$ (Licht et al. 2015, fig. 4).

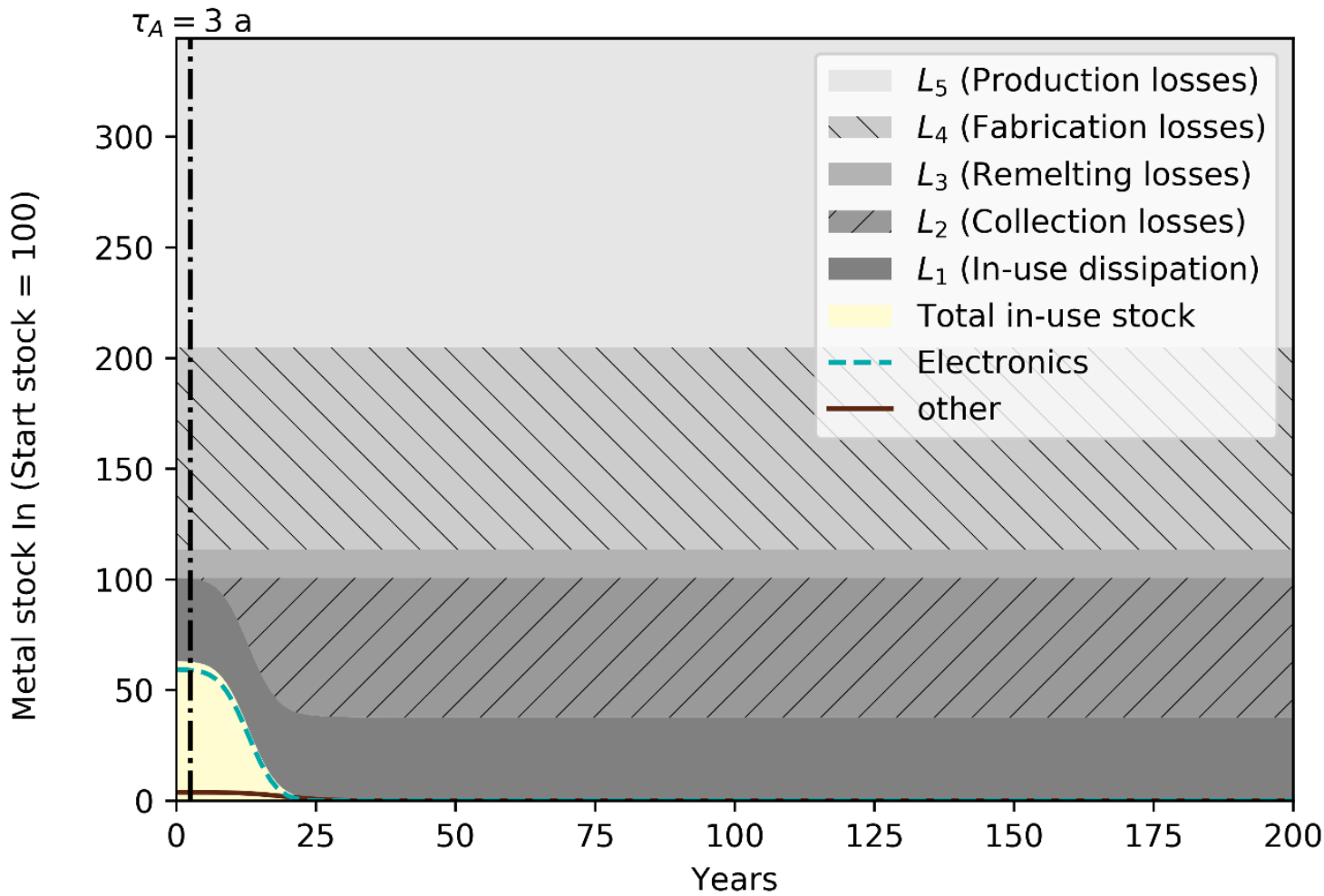

Figure S24: Metal stocks of a primary production cohort of indium in the anthroposphere by demand sectors and dissipative losses. Remelting losses are negligibly small. 


\section{$2.13 \quad$ Tin}

Tin material flows displayed in Figure S25 are identical to the "global tin cycle, 1927-2005" by (Izard and Müller 2010, fig. 1). Note that these are cumulative flows over the whole period, not a single year. Parallel processes in production, manufacturing and the use phase are jointly displayed.

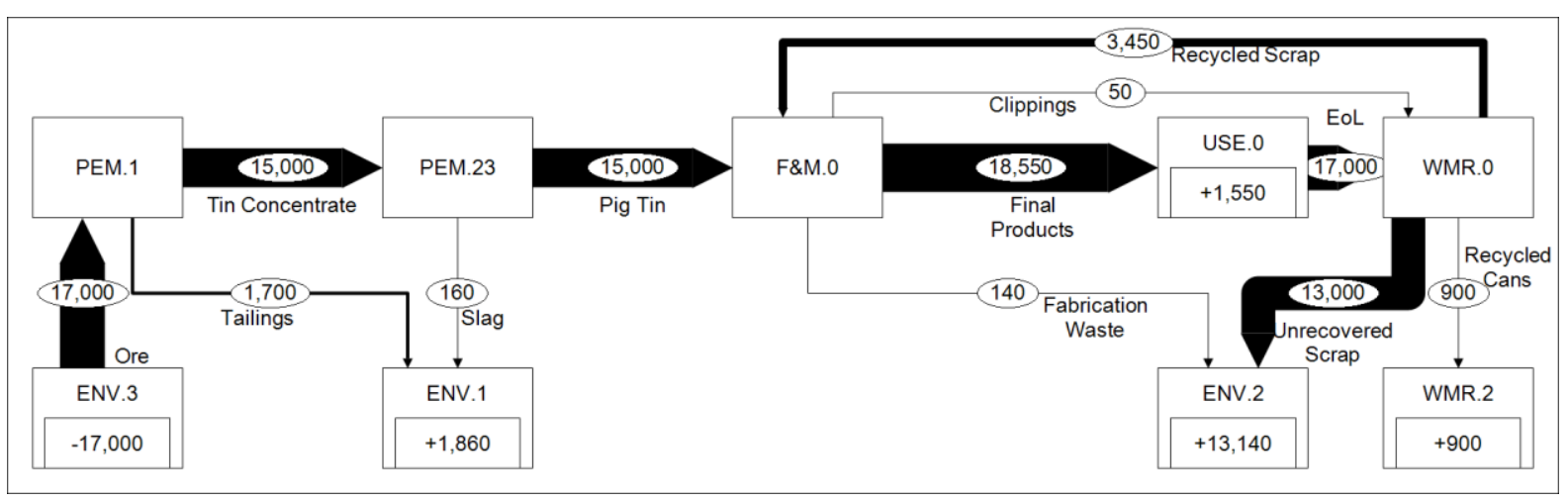

Figure S25: Global metal cycle for tin for the years 1927 until 2005 in kilotons (1 kt = $1 \mathrm{Gg}$ ) (Izard and Müller 2010, fig. 1).

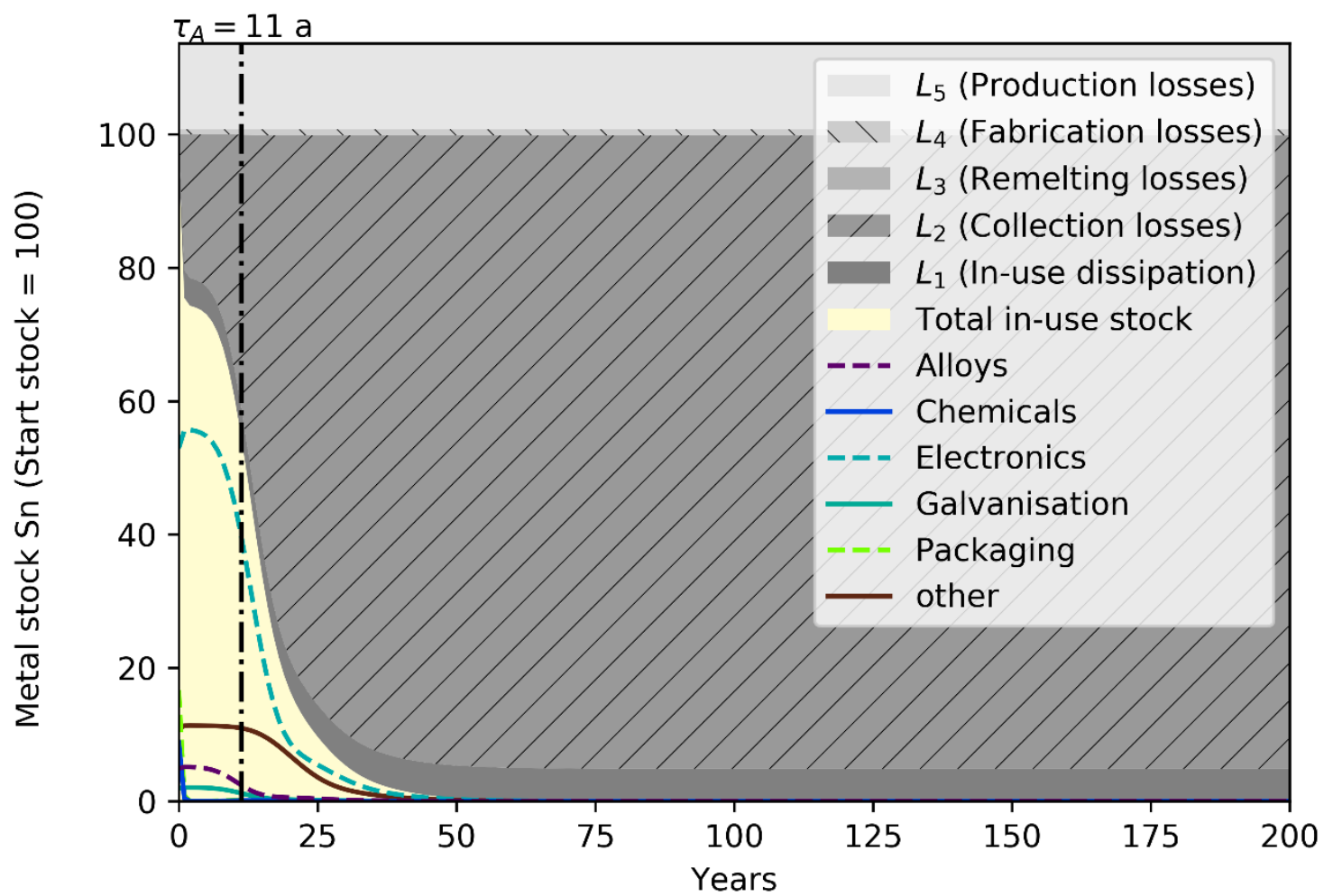

Figure S26: Metal stocks of a primary production cohort of tin in the anthroposphere by demand sectors and dissipative losses. Remelting losses are negligibly small. 
Postprint Helbig et al. (2020): Resources, Conservation and Recycling 153, 104537

https://doi.org/10.1016/j.resconrec.2019.104537

\section{$2.14 \quad$ Tellurium}

Tellurium material flows displayed in Figure S27 are identical to the "global tellurium [cycle] for the [year] [...] 2010" by (Kavlak and Graedel 2013b, fig. 3d).

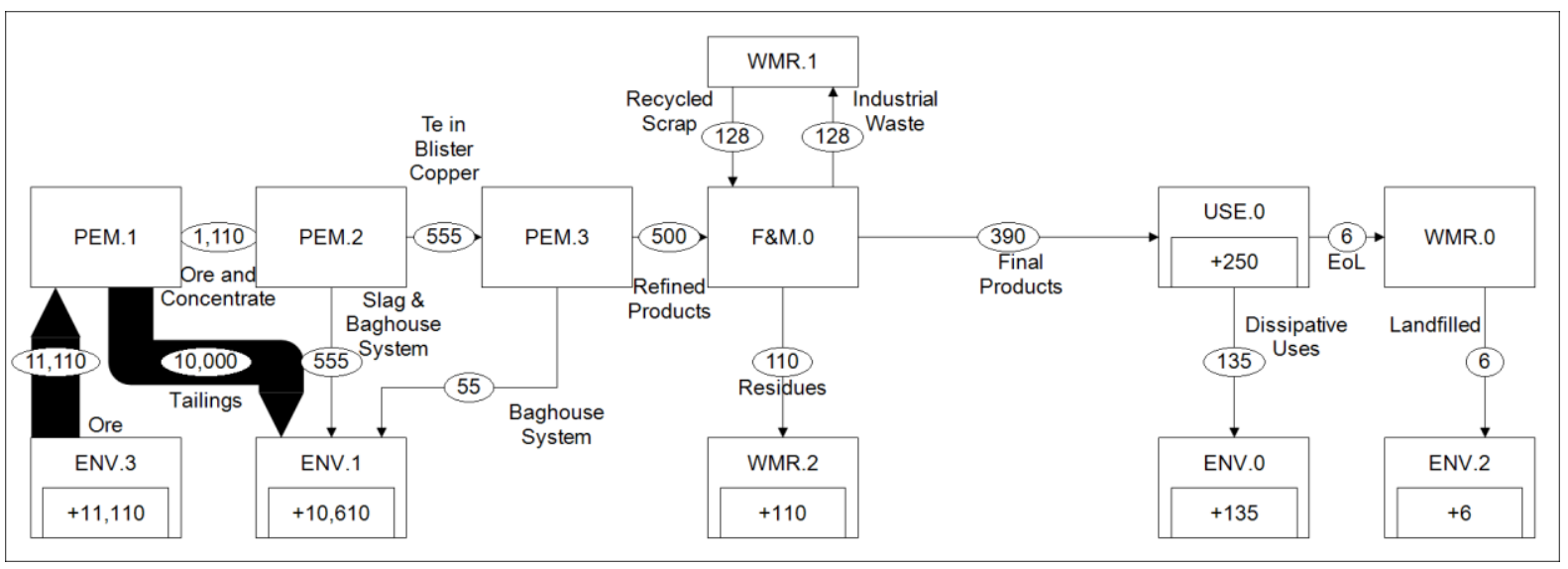

Figure S27: Global metal cycle for tellurium for the year 2010 in metric tons ( $1 \mathrm{t}=1 \mathrm{Mg}$ ) (Kavlak and Graedel 2013b, fig. 3d).

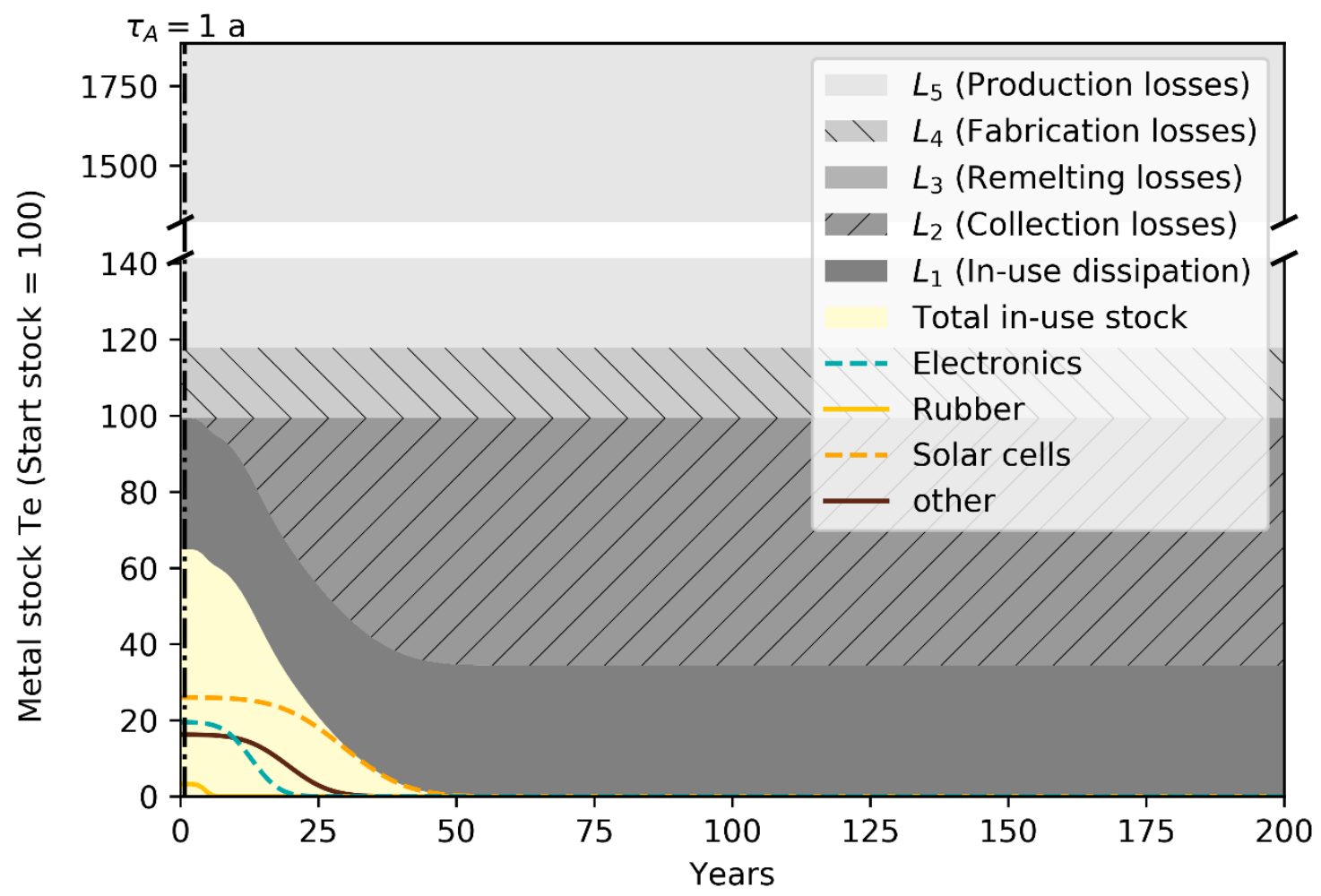

Figure S28: Metal stocks of a primary production cohort of tellurium in the anthroposphere by demand sectors and dissipative losses. Remelting losses are negligibly small. Ordinate is broken in the area of Production losses. 


\subsection{Tantalum}

Tantalum material flows displayed in Figure S29 are recalculated from the Sankey diagram without numerical values on the "global anthropogenic tantalum cycle for [year] [...] 2015" of (Nassar 2017, fig. 2).

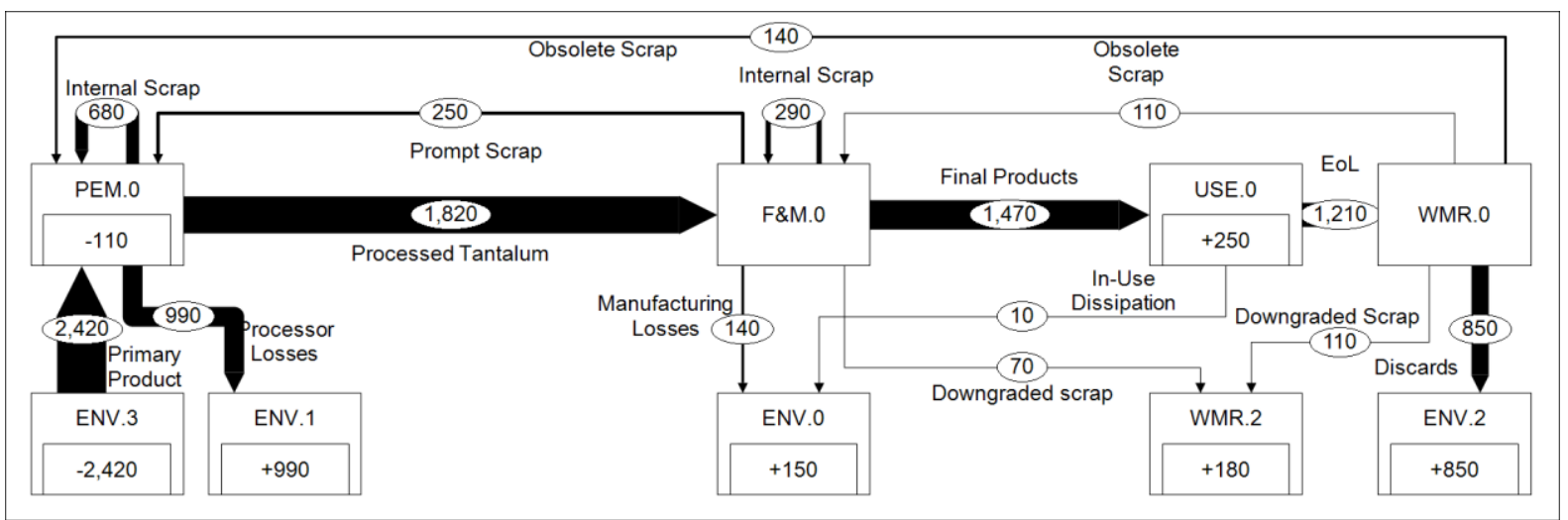

Figure S29: Global metal cycle for tantalum for the year 2015 in metric tons (1 t = $1 \mathrm{Mg}$ ) (Nassar 2017, fig. 2).

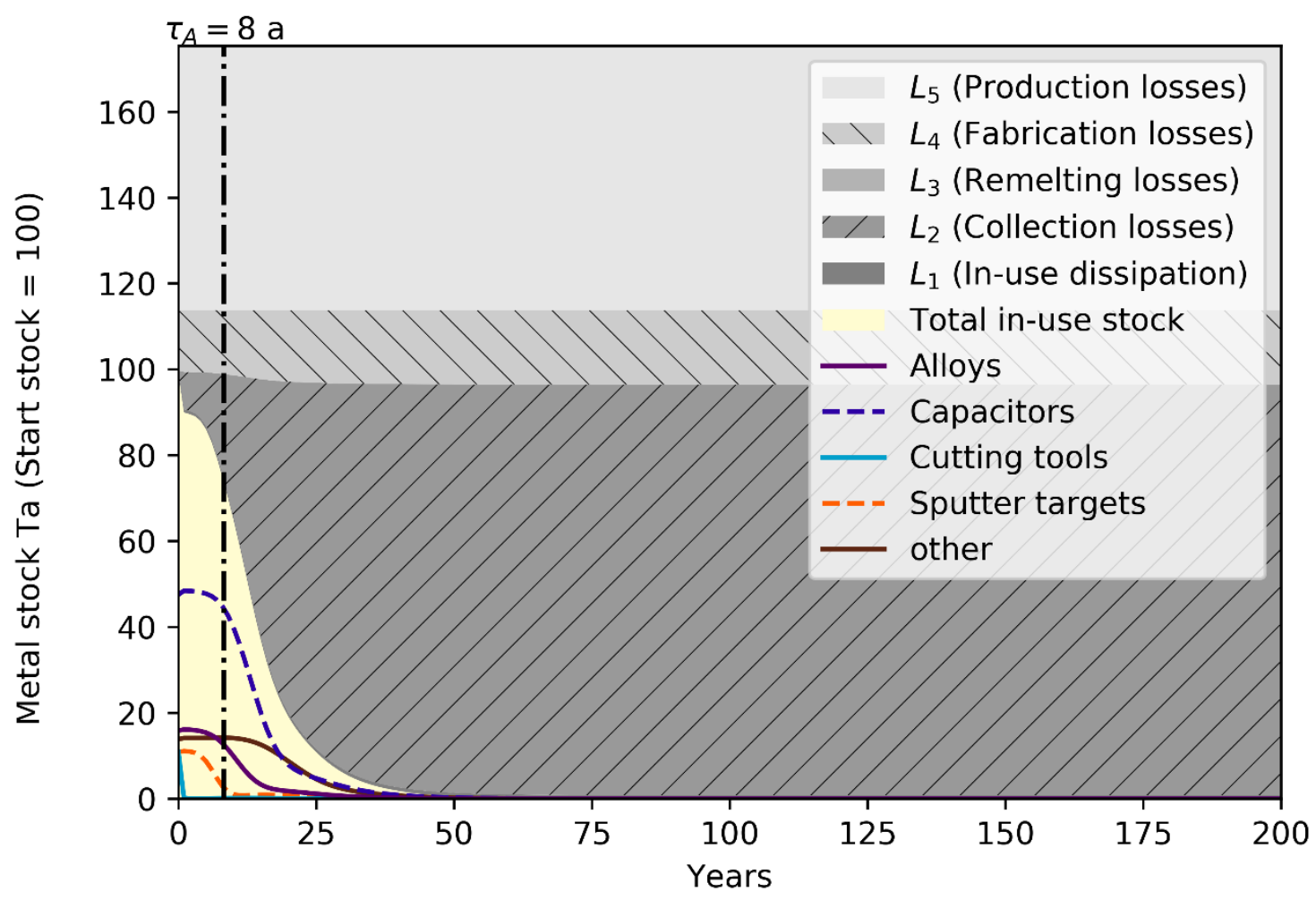

Figure S30: Metal stocks of a primary production cohort of tantalum in the anthroposphere by demand sectors and dissipative losses. Remelting losses and In-use dissipation are negligibly small. 
Postprint Helbig et al. (2020): Resources, Conservation and Recycling 153, 104537

https://doi.org/10.1016/j.resconrec.2019.104537

\subsection{Tungsten}

Tungsten material flows displayed in Figure S31 are identical to the "global [cycle] of [...] tungsten in 2008" by (Meylan et al. 2015, fig. 3)

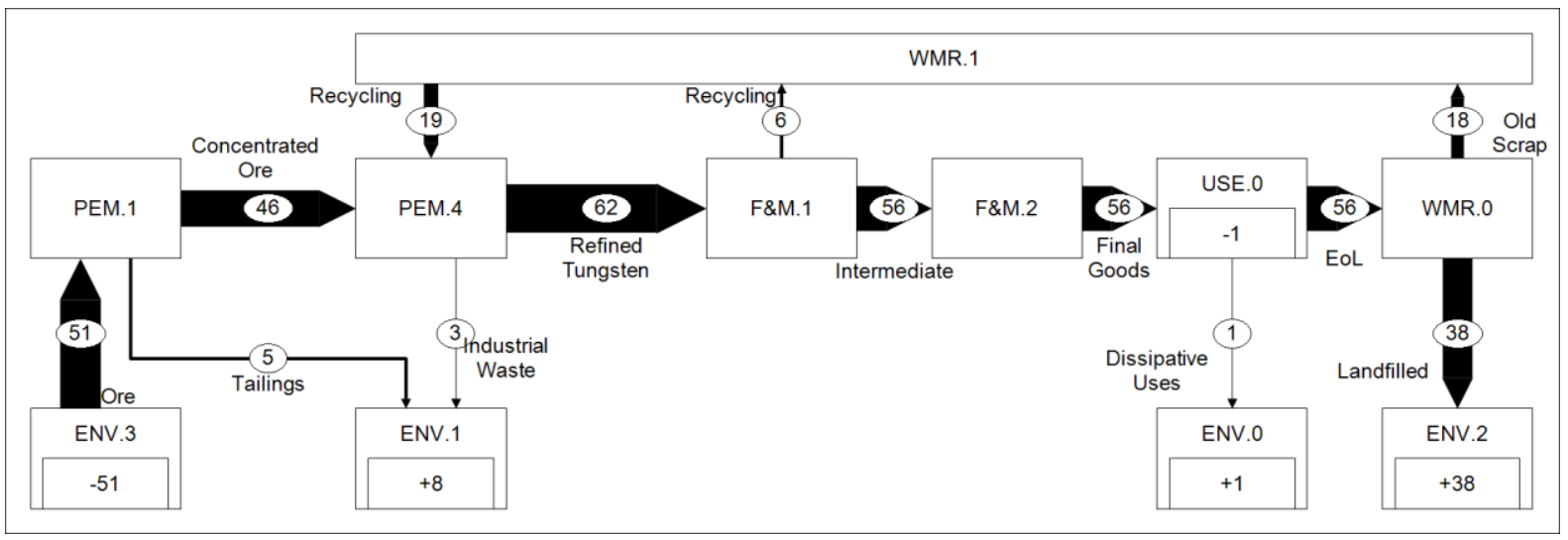

Figure S31: Global metal cycle for tungsten for the year 2008 in kilotons (1 kt = $1 \mathrm{Gg}$ ) (Meylan et al. 2015, fig. 3).

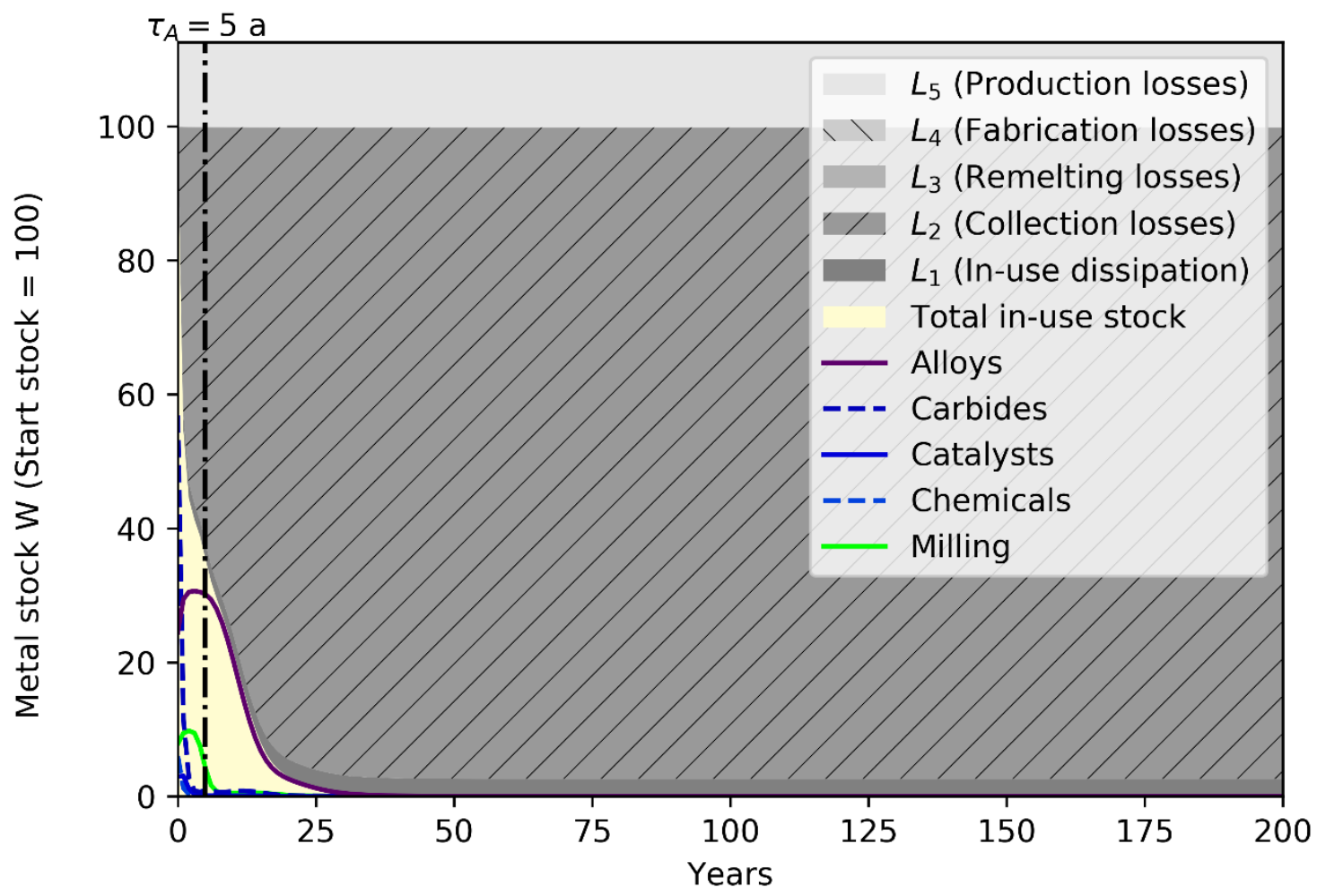

Figure S32: Metal stocks of a primary production cohort of tungsten in the anthroposphere by demand sectors and dissipative losses. Fabrication losses and Remelting losses are negligibly small. 
Postprint Helbig et al. (2020): Resources, Conservation and Recycling 153, 104537

https://doi.org/10.1016/j.resconrec.2019.104537

\subsection{Rhenium}

Rhenium material flows displayed in Figure S33 are identical to the "global [cycle] of [...] rhenium [...] in 2018" by (Meylan et al. 2015, fig. 3).

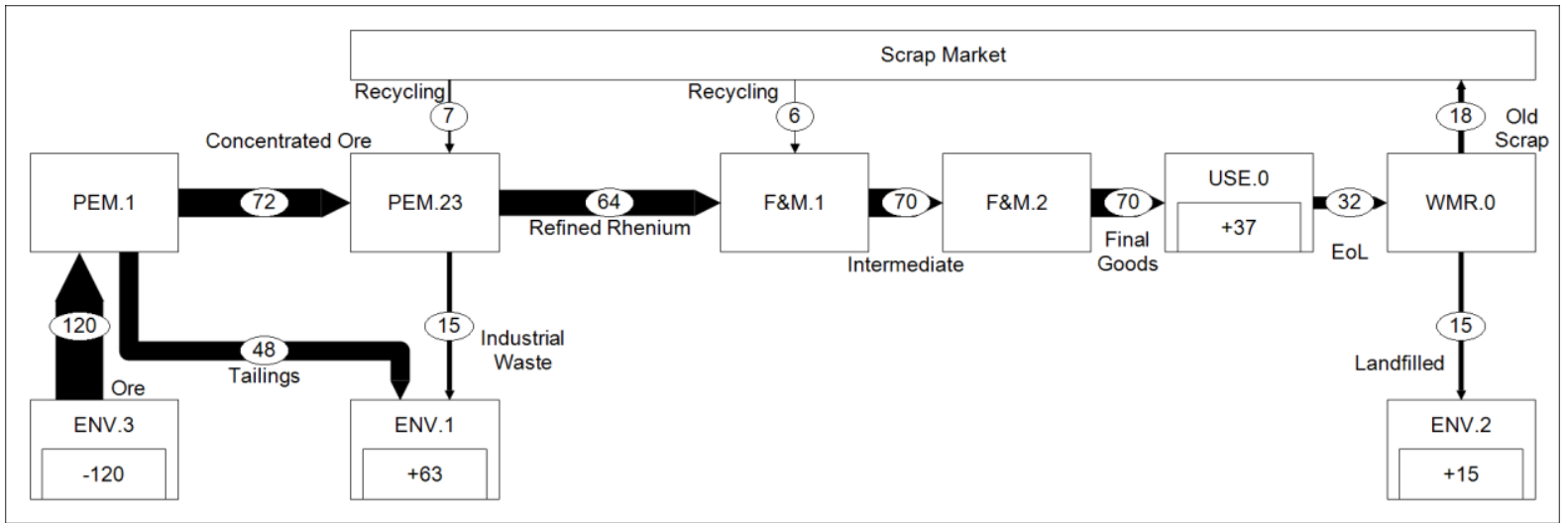

Figure S33: Global metal cycle for rhenium for the year 2008 in metric tons (1 t = $1 \mathrm{Mg}$ ) (Meylan et al. 2015, fig. 3).

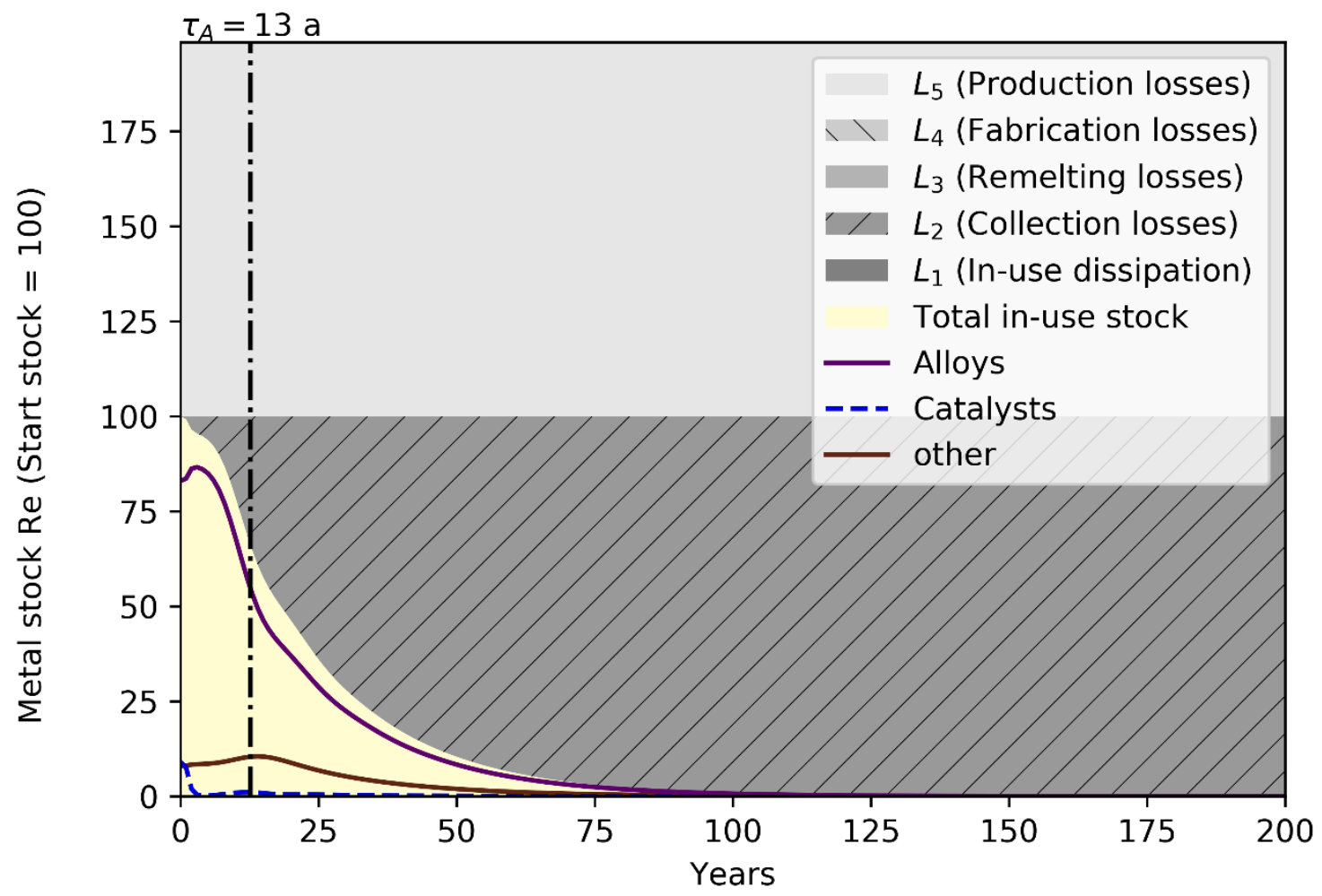

Figure S34: Metal stocks of a primary production cohort of rhenium in the anthroposphere by demand sectors and dissipative losses. Fabrication losses, Remelting losses and In-use dissipation are negligibly small. 
Postprint Helbig et al. (2020): Resources, Conservation and Recycling 153, 104537 https://doi.org/10.1016/j.resconrec.2019.104537

2.18 Lead

Lead material flows displayed in Figure S35 are identical to the "global best estimate anthropogenic lead cycle for 2000" by (Mao et al. 2008, fig. 4b).

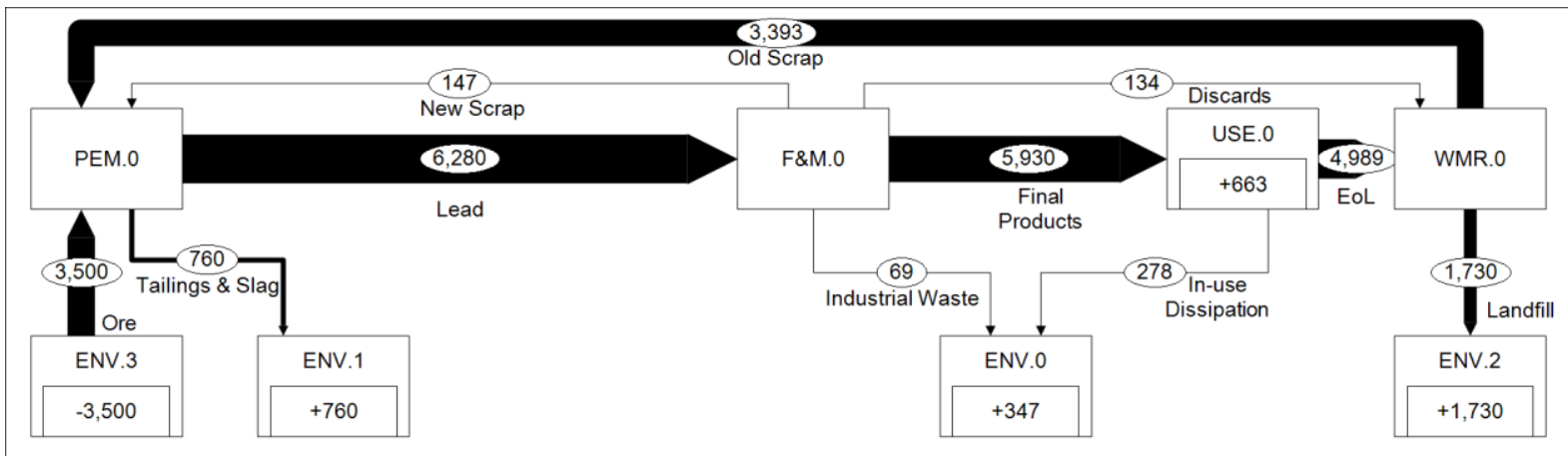

Figure S35: Global metal cycle for lead for the year 2000 in kilotons (1 kt = $1 \mathrm{Gg}$ ) (Mao et al. 2008, fig. 4b).

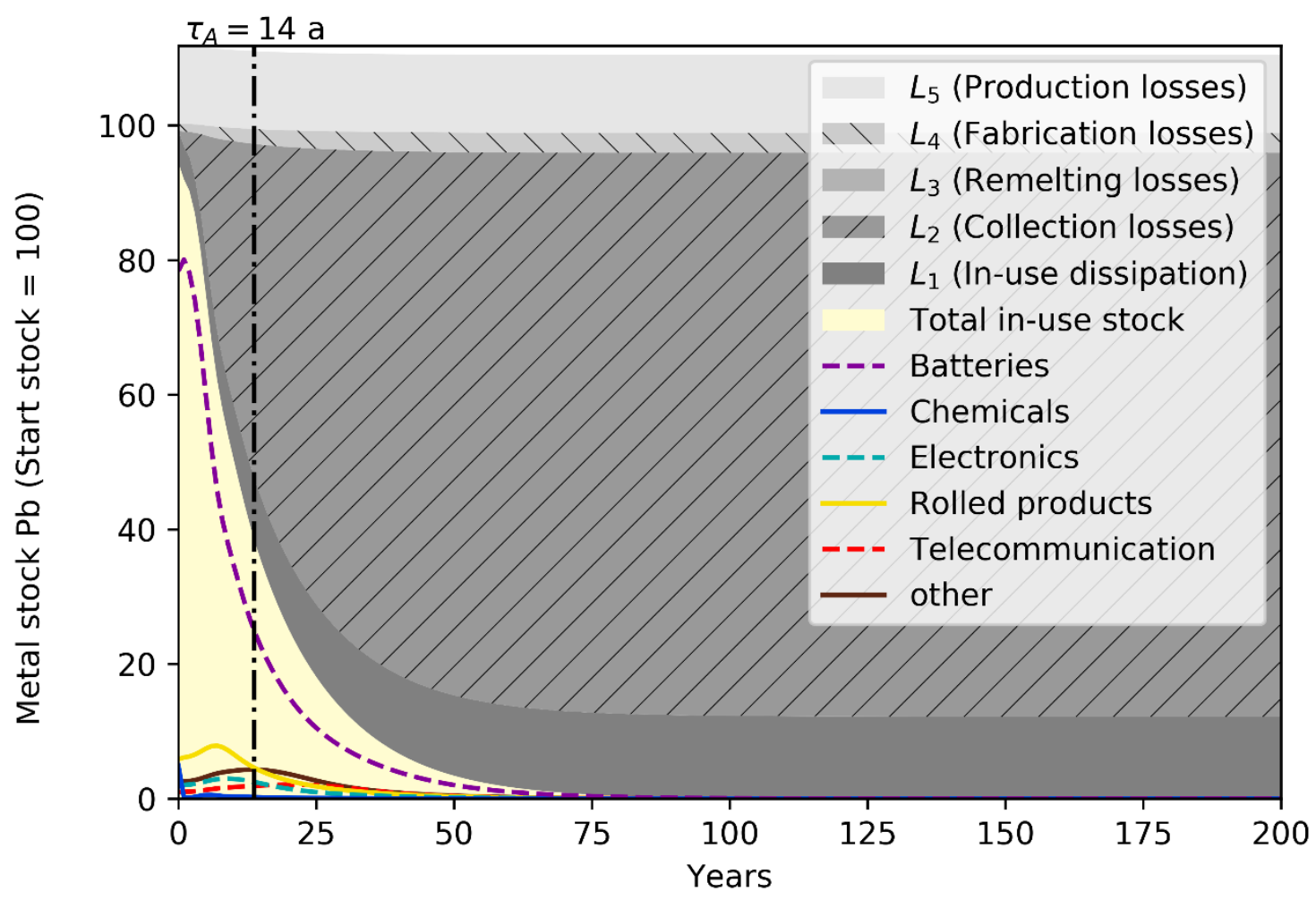

Figure S36: Metal stocks of a primary production cohort of lead in the anthroposphere by demand sectors and dissipative losses. Remelting losses are negligibly small. 


\section{References}

Bertram, M., S. Ramkumar, H. Rechberger, G. Rombach, C. Bayliss, K.J. Martchek, D.B. Müller, and G. Liu. 2017. A regionally-linked, dynamic material flow modelling tool for rolled, extruded and cast aluminium products. Resources, Conservation and Recycling 125: 48-69. http://linkinghub.elsevier.com/retrieve/pii/S0921344917301520.

Glöser-Chahoud, S. 2017. Quantitative Analyse der Kritikalität mineralischer und metallischer Rohstoffe unter Verwendung eines systemdynamischen Modell-Ansatzes. TU Clausthal.

Glöser, S., M. Soulier, and L.A. Tercero Espinoza. 2013. Dynamic analysis of global copper flows. Global stocks, postconsumer material flows, recycling indicators, and uncertainty evaluation. Environmental Science and Technology 47(12): 6564-6572. http://dx.doi.org/10.1021/Es400069b.

Harper, E.M., G. Kavlak, and T.E. Graedel. 2012. Tracking the metal of the goblins: Cobalt's cycle of use. Environmental Science \& Technology 46(2): 1079-1086. http://dx.doi.org/10.1021/es201874e.

Izard, C.F. and D.B. Müller. 2010. Tracking the devil's metal: Historical global and contemporary U.S. tin cycles. Resources, Conservation and Recycling 54(12): 1436-1441. http://linkinghub.elsevier.com/retrieve/pii/S092134491000145X.

Johnson, J.X., J. Jirikowic, M. Bertram, D. van Beers, R.B. Gordon, K. Henderson, R.J. Klee, et al. 2005. Contemporary Anthropogenic Silver Cycle: A Multilevel Analysis. Environmental Science \& Technology 39(12): 4655-4665. http://pubs.acs.org/doi/abs/10.1021/es048319x.

Johnson, J.X., L. Schewel, and T.E. Graedel. 2006. The contemporary anthropogenic chromium cycle. Environmental Science and Technology 40(22): 7060-7069.

Kavlak, G. and T.E. Graedel. 2013a. Global anthropogenic selenium cycles for 1940-2010. Resources, Conservation and Recycling 73: 17-22. http://dx.doi.org/10.1016/j.resconrec.2013.01.013.

Kavlak, G. and T.E. Graedel. 2013b. Global anthropogenic tellurium cycles for 1940-2010. Resources Conservation and Recycling 76: 21-26. http://dx.doi.org/10.1016/j.resconrec.2013.04.007.

Licht, C., L.T. Peiró, and G. Villalba. 2015. Global Substance Flow Analysis of Gallium, Germanium, and Indium: Quantification of Extraction, Uses, and Dissipative Losses within their Anthropogenic Cycles. Journal of Industrial Ecology 19(5): 890-903. http://doi.wiley.com/10.1111/jiec.12287.

Mao, J., J. Dong, and T.E. Graedel. 2008. The multilevel cycle of anthropogenic lead. II. Results and discussion. Resources, Conservation and Recycling 52(8-9): 1050-1057. http://dx.doi.org/10.1016/j.resconrec.2008.04.005.

Meylan, G. and B.K. Reck. 2017. The anthropogenic cycle of zinc: Status quo and perspectives. Resources, Conservation and Recycling 123: 1-10. http://linkinghub.elsevier.com/retrieve/pii/S0921344916300064.

Meylan, G., B.K. Reck, and T.E. Graedel. 2015. Comprehensive Global and United States Cycles of Gallium, Germanium, Rhenium, and Tungsten in 2008: Final report on USGS Research Grant G14AP00059. https://www.usgs.gov/media/files/mrerp-report-g14ap00059-pdf-861-kb

Nassar, N.T. 2017. Shifts and trends in the global anthropogenic stocks and flows of tantalum. Resources, Conservation and Recycling 125(June): 233-250. http://dx.doi.org/10.1016/j.resconrec.2017.06.002.

Reck, B.K. and V.S. Rotter. 2012. Comparing Growth Rates of Nickel and Stainless Steel Use in the Early 2000s. Journal of Industrial Ecology 16(4): 518-528. http://dx.doi.org/10.1111/j.15309290.2012.00499.x.

Wang, T., D.B. Müller, and T.E. Graedel. 2007. Forging the anthropogenic iron cycle. Environmental Science and Technology 41(14): 5120-5129. 